\title{
Liana optical traits increase tropical forest albedo and reduce ecosystem productivity
}

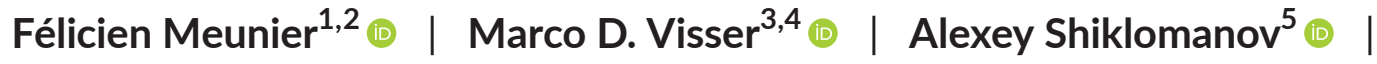

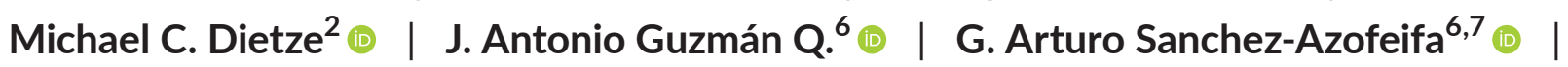

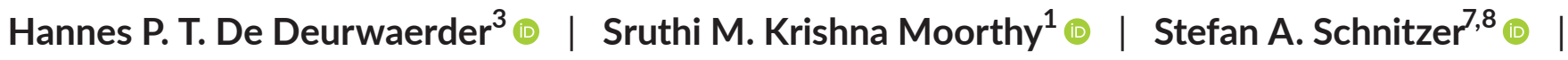

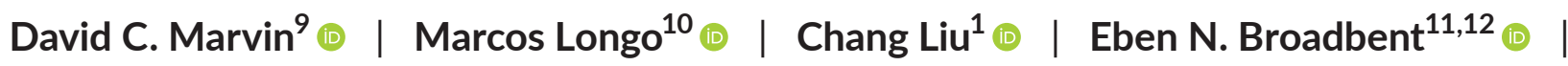

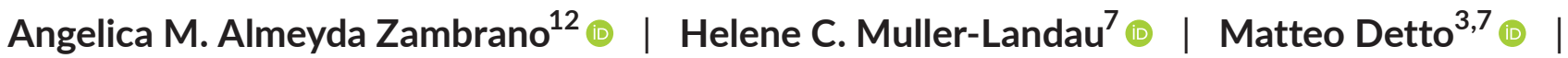 \\ Hans Verbeeck ${ }^{1}$ [ \\ ${ }^{1}$ CAVElab-Computational and Applied Vegetation Ecology, Department of Environment, Ghent University, Ghent, Belgium \\ ${ }^{2}$ Department of Earth and Environment, Boston University, Boston, Massachusetts, USA \\ ${ }^{3}$ Department of Ecology and Evolutionary Biology, Princeton University, Princeton, New Jersey, USA \\ ${ }^{4}$ Institute of Environmental Sciences, Leiden University, Leiden, The Netherlands \\ ${ }^{5}$ NASA Goddard Space Flight Center, Greenbelt, Maryland, USA \\ ${ }^{6}$ Centre for Earth Observation Sciences (CEOS), Earth and Atmospheric Sciences Department, University of Alberta, Edmonton, Alberta, Canada \\ ${ }^{7}$ Smithsonian Tropical Research Institute, Balboa, Panama \\ ${ }^{8}$ Department of Biological Sciences, Marquette University, Milwaukee, Wisconsin, USA \\ ${ }^{9}$ Salo Sciences, Inc., San Francisco, California, USA \\ ${ }^{10}$ Jet Propulsion Laboratory, California Institute of Technology, Pasadena, California, USA \\ ${ }^{11}$ Spatial Ecology and Conservation (SPEC) Lab, School of Forest, Fisheries, and Geomatics Sciences, University of Florida, Gainesville, Florida, USA \\ ${ }^{12}$ Spatial Ecology and Conservation (SPEC) Lab, Center for Latin American Studies, University of Florida, Gainesville, Florida, USA
}

\section{Correspondence}

Félicien Meunier, CAVElab-

Computational and Applied Vegetation Ecology, Department of Environment,

Ghent University, Ghent, Belgium.

Email: felicien.meunier@gmail.com

Funding information

H2020 European Research Council, Grant/Award Number: 637643; Fonds Wetenschappelijk Onderzoek, Grant/ Award Number: $1214720 \mathrm{~N}$ and G002321N; NSF, Grant/Award Number: 1458021; NASA; USDA; University of Florida

\begin{abstract}
Lianas are a key growth form in tropical forests. Their lack of self-supporting tissues and their vertical position on top of the canopy make them strong competitors of resources. A few pioneer studies have shown that liana optical traits differ on average from those of colocated trees. Those trait discrepancies were hypothesized to be responsible for the competitive advantage of lianas over trees. Yet, in the absence of reliable modelling tools, it is impossible to unravel their impact on the forest energy balance, light competition, and on the liana success in Neotropical forests. To bridge this gap, we performed a meta-analysis of the literature to gather all published liana leaf optical spectra, as well as all canopy spectra measured over different levels of liana infestation. We then used a Bayesian data assimilation framework applied to two radiative transfer models (RTMs) covering the leaf and canopy scales to derive tropical tree and liana trait distributions, which finally informed a full dynamic vegetation model. According to the RTMs inversion, lianas grew thinner, more horizontal leaves
\end{abstract}


with lower pigment concentrations. Those traits made the lianas very efficient at light interception and significantly modified the forest energy balance and its carbon cycle. While forest albedo increased by $14 \%$ in the shortwave, light availability was reduced in the understorey ( $-30 \%$ of the PAR radiation) and soil temperature decreased by $0.5^{\circ} \mathrm{C}$. Those liana-specific traits were also responsible for a significant reduction of tree $(-19 \%)$ and ecosystem $(-7 \%)$ gross primary productivity (GPP) while lianas benefited from them (their GPP increased by $+27 \%$ ). This study provides a novel mechanistic explanation to the increase in liana abundance, new evidence of the impact of lianas on forest functioning, and paves the way for the evaluation of the large-scale impacts of lianas on forest biogeochemical cycles.

\section{KEYWORDS}

ecosystem demography model (ED2), forest albedo, forest energy balance, PROSPECT-5, radiative transfer models, structural parasitism, tropical lianas

\section{1 | INTRODUCTION}

Terrestrial ecosystems are a key component of the Earth's carbon cycle as they are responsible for a yearly uptake of about $60 \mathrm{GtC}$ (Beer et al., 2010) and store about 860 GtC worldwide (Pan et al., 2011), about $50 \%$ of which is located in the tropics (Avitabile et al., 2016; Brinck et al., 2017). Forests in general, and tropical ecosystems in particular, also profoundly regulate the global energy budget by mediating the exchange of energy and moisture between the land and the atmosphere (Fischlin et al., 2007; Piao et al., 2020; Spracklen et al., 2018). Through succession, land use, management, and vegetation dynamics, the ratio of back-reflected solar radiation to the total received (i.e. albedo) may radically change (Bonan, 2008).

Forest albedo is controlled by the optical properties and geometric arrangement of leaf and wood tissues, and, in open canopies, also by the contribution of soil reflectivity. Altogether, these forest features determine what fraction of incident light penetrates in the canopy, to what depth, where light is absorbed, and how much is reflected back to the atmosphere (Asner, 2008). Light interception and light availability within the canopy not only regulate photosynthesis but also influence long-term processes like seedling recruitment, and hence forest species composition through competition (Bonan, 2019). In other words, radiative transfer is a key process for all plants in the ecosystem (Yuan et al., 2016) and its accurate representation in vegetation models is critical to represent ecosystem functioning (Fisher et al., 2018).

While radiative transfer in canopies has been studied for decades (Jacquemoud et al., 2000), as of today there has been little focus on its contribution to uncertainty in dynamic global vegetation models (Viskari et al., 2019). However, as light is often the limiting resource in dense tropical canopies, it plays a critical role for plant growth and development, often driving intraspecies and interspecies competition and succession (Bongers \& Sterck, 1998; Poorter et al., 2003). Moreover, in the context of global warming, a change of tropical ecosystem albedo might have important feedbacks on the regional climate (Piao et al., 2020).

Lianas are woody vines that are abundant in tropical ecosystems (Schnitzer, 2005) where they act as structural parasites of the forest (Stevens, 1987). They climb up the stems of other plants to reach the top of the canopy from which they compete for light and progressively displace a significant fraction of tree leaf biomass with their own (Kazda \& Salzer, 2000; Schnitzer et al., 2005; Selaya \& Anten, 2008). In tropical forests, lianas play a key role in vegetation dynamics as they represent on average $25 \%$ of the woody stems (Dewalt et al., 2014; Schnitzer \& Bongers, 2002) and contribute to $9 \%-31 \%$ of the total leaf area (van der Heijden et al., 2013).

Previous studies have demonstrated that the leaf spectral signature can significantly differ between tropical trees and lianas (Castro-Esau et al., 2004; Guzmán et al., 2018; Kalacska et al., 2007; Sánchez-Azofeifa et al., 2009). These findings are consistent with multiple observations of growth form-level differences in leaf biochemical traits. In particular, in a pantropical leaf trait analysis, Asner and Martin (2012) found larger mass-based concentrations of light capturegrowth chemicals (chlorophyll, carotenoid) and smaller leaf mass per area in liana leaves which might be responsible for those spectral differences. Similarly, Wyka et al. (2013) showed in a large meta-analysis that lianas exhibit lower leaf mass per area and higher mass-based photosynthetic rates and nutrient ( $\mathrm{N}$ and $\mathrm{P}$ ) concentrations. These differences between lianas and trees (potentially in combination with differences in leaf angle distributions and canopy clumping) might also explain why a few seminal studies have observed an increase in albedo in canopies with high liana coverages (Kalacska et al., 2007; Marvin et al., 2016; Sánchez-Azofeifa \& Castro-Esau, 2006). Liana leaves, because of their vertical position in the canopy and these biochemical properties contrasting with those of trees, could impact forest functioning by increasing forest albedo and reducing light availability in the understorey. Forest energy balance might therefore significantly differ in liana-free and liana-rich patches. We argue that a significant part of the changes of albedo observed by remote sensing in tropical forests 
(Doughty et al., 2018; Piao et al., 2020) might be due to liana infestation variability. This hypothesis is especially relevant to test in the context of increasing liana abundance observed in the Neotropics (Phillips, 2002; Schnitzer \& Bongers, 2011), which could aggravate the impact of lianas on radiative transfer of tropical forests in the near future.

Despite their potential impact on forest biogeochemical cycles, lianas have generally been ignored in vegetation models and remote sensing products (Moorthy \& Sruthi, 2019; Verbeeck \& Kearsley, 2016). However, the recent implementation of the lianescent growth form in the Ecosystem Demography model (di Porcia e Brugnera et al., 2019; Meunier et al., 2020) now supports evaluating the role of lianas on the energy budget of tropical ecosystems under changing environmental conditions. Because vegetation models combine the biophysics of land surface models with vegetation demography and biogeochemistry (Dietze et al., 2014; Fisher et al., 2014; Purves $\&$ Pacala, 2008), they are excellent candidates for studying and projecting the impacts of climate change and resulting forest composition evolution (such as liana proliferation) on the radiation profile and forest albedo (Fisher et al., 2018).

The objective of this study is to investigate how lianas influence the energy budget and the biogeochemical cycles of tropical forests by altering light interception. We hypothesize that liana-specific optical traits (such as lower leaf mass per area, larger mass-based concentrations of light capture-growth chemicals, horizontal leaves) are responsible for a disproportionate light interception by liana leaves, which results in (i) a decreased understorey light availability, (ii) an increased albedo, and (iii) a decline of tree productivity in heavily infested forest patches.

\section{2 | MATERIALS AND METHODS}

To estimate the impact of liana-specific traits on the radiative transfers of tropical forests, we first assembled a database of liana leaf-level reflectance measurements from literature, along with stand-level reflectance spectra covering different levels of liana infestation. We assimilated the collected spectra to derive leaf biochemical and canopy structural properties using leaf-level (PROSPECT-5) and stand-level (ED-RTM) radiative transfer models and estimate how those traits diverge between tropical trees and lianas. We then ran simulations of a process-based vegetation model (ED2.2), in which lianas were in turn characterized by liana or tree parameter distributions. We validated the principal findings of this study with independent experimental datasets (WorldView-3 and GatorEye UAV-LiDAR). The overall workflow of this study is illustrated in Figure 1.

\section{1 | Model description}

\subsubsection{The PROSPECT-5 model}

The PROSPECT- 5 model simulates the spectral reflectance and transmittance of a leaf over a large wavelength range covering the visible
(400-700 nm), near infrared (700-1400 nm), and short-wave infrared (1500-2500 nm) at the nanometer resolution. PROSPECT-5 represents leaves as stacks of partially reflective/transparent layers and is based on five biochemical and structural properties, namely the total chlorophyll (Cab) and Carotenoid (Car) contents, the number of stacked elementary homogeneous layers ( $N_{\text {layers }}$ ), the leaf equivalent water thickness $\left(C_{\mathrm{w}}\right)$ and its dry matter content (LMA; Feret et al., 2008). Wavelength-specific reflectivity and transmissivity coefficients are then calculated as a weighted linear combination of the empirically calibrated absorption spectra for leaf pigments, water, and dry matter (Feret et al., 2008). Table 1 summarizes the parameters discussed in this study, together with their units and their description.

\subsection{2 | The Ecosystem Demography model, version 2}

\section{Overview of the vegetation model}

The Ecosystem Demography model version 2.2 (ED2.2) is a vegetation model that simulates forest biophysical and physiological cycles, and accounts for horizontal and vertical heterogeneities of the ecosystem (Longo et al., 2019a). Carbon, water, and energy cycles are solved for individual forest patches, each containing zero, one, or several plant cohorts. Patches are defined as areas of the forest with similar age (i.e. disturbance history) while cohorts are groups of plants in a patch with similar size ( $\mathrm{DBH})$, belonging to the same plant functional type (PFT), and characterized by a dynamic plant density $\left(n_{k}\right)$. In ED2, patches and cohorts are spatially implicit, which means that the position of patches relative to one another and the horizontal position of each plant are not simulated (Medvigy et al., 2009). Yet, plants grow in an environment (soil, climate) defined by the coordinates of the simulated site (Longo et al., 2019a) and the structure of the canopy is vertically resolved.

Previous studies have demonstrated the ability of the ED2.2 model to reproduce important aspects of carbon and water dynamics in tropical ecosystems (Longo et al., 2019b). In particular, it was shown that ED2 could correctly simulate reductions in aboveground biomass of Amazon forests subjected to drought experiments (Powell et al., 2013), capture mortality rates, and aboveground biomass stocks on Barro Colorado Island (BCl), Panama (Powell et al., 2017), and represent leaf and biomass spatial and temporal variability in tropical dry forests (Xu et al., 2016). Recently, a new plant functional type accounting for the lianescent growth form was implemented in the ED2 model by di Porcia e Brugnera et al. (2019). The liana PFT was extensively calibrated by Meunier et al. (2020), but that calibration did not include radiative transfer parameters.

The radiative transfer model of ED2

In ED2, the radiative transfer is modelled as a multi-layer version of the two-stream model (Liou, 2002; Sellers, 1985) applied to three broad spectral bands: visible (400-700 nm), solar (near and shortwave) infrared (700-3000 nm), and thermal infrared radiation (3-15 $\mu \mathrm{m})$. The two-stream approach is the core canopy radiative transfer model of 


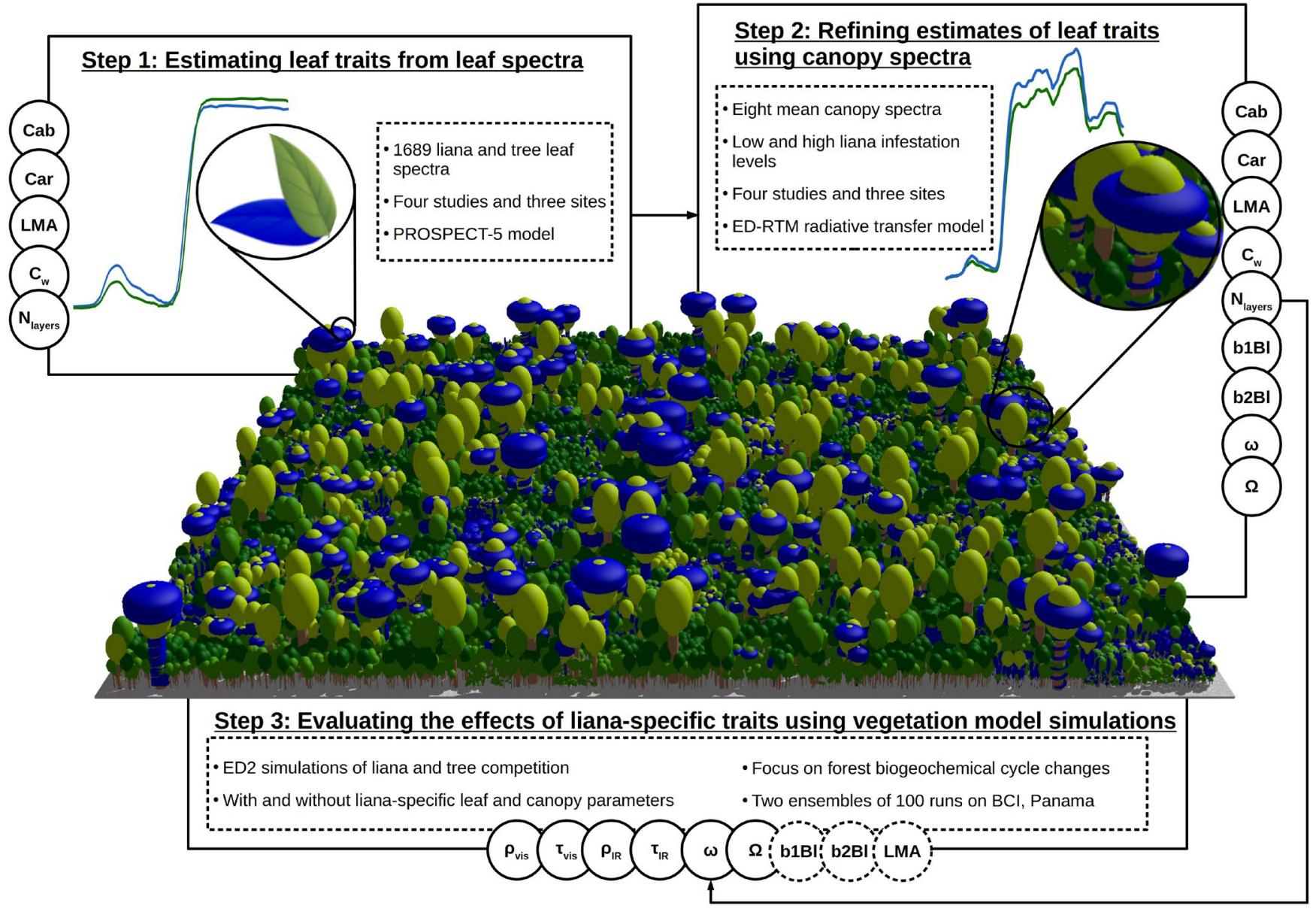

FIGURE 1 Workflow of the study as divided in three steps. Observed leaf spectra of both lianas and trees were assimilated to optimize leaf biochemical parameters of those PFTs through PROSPECT-5 simulations (Step 1). Leaf optical and biochemical traits were further calibrated in a radiative transfer model (ED-RTM) together with liana and tree canopy parameters through the assimilation of canopy reflectance spectral data under low and high liana infestation levels (Step 2). The resulting parameter posterior distributions then served to evaluate the impact of liana leaf parameters in a vegetation model (ED2.2) in simulations with and without liana-specific leaf and canopy parameters. In these runs, liana LAI-related parameters (b1BI, b2BI, and LMA) were systematically sampled from liana parameter distributions to conserve a similar ecosystem LAI. In steps 1 and 2, all parameters indicated on the side were optimized to fit observational data within a Bayesian framework. Throughout the manuscript, lianas (and liana-rich forest stands) are consistently represented in blue

multiple global vegetation models, including JULES (Best et al., 2011) and CLM (Lawrence et al., 2019; Oleson et al., 2013). In this study, we focused on the visible and solar infrared bands as we wanted to test the impact of liana traits on short-wave radiation.

In ED2, the radiation regime is based on single scattering and backscattering coefficients computed from prescribed PFT-specific leaf transmissivity ( $\tau_{\text {vis }}$ and $\tau_{\mathrm{IR}}$ for the visible and solar infrared bands, respectively) and reflectivity $\left(\rho_{\text {vis }}\right.$ and $\left.\rho_{\mathrm{IR}}\right)$ coefficients, as well as a leaf orientation parameter $\omega$ and the vertical structure of the canopy. Leaf orientation $\omega$ is a PFT-specific parameter that determines the average leaf surface area in the direction of the radiation beam. It varies between -1 (all leaves are vertically oriented) and +1 (all leaves are horizontally oriented), with 0 meaning randomly oriented leaves. The vertical structure of the canopy is determined by the size distribution of the plant cohorts within each patch. Each cohort $k$ is represented by a flat-topped layer whose vertical position $h_{k}$ is scaled with its diameter $\mathrm{DBH}_{\mathrm{k}}$ according to a Weibull function:

$$
h_{\mathrm{k}}=h_{\mathrm{ref}} \cdot\left(1-\exp \left(-b 1 H t \cdot \mathrm{DBH}_{\mathrm{k}}^{b 2 H t}\right)\right)
$$

where $h_{\text {ref, }}, b 1 \mathrm{Ht}$ and $b 2 \mathrm{Ht}$ are PFT-specific allometric parameters. As opposed to trees, liana vertical position is not only determined by their size but also by the height distribution of the trees in the vicinity: in the model, lianas can only overtop trees belonging to the same patch by a small threshold because they lack self-supporting tissues (Meunier et al., 2020). Liana initial height was determined by their size and the height distribution of the surrounding trees so that all lianas with a stem diameter $>3 \mathrm{~cm}$ reached the top of the forest canopy, resulting in a liana vertical clumping (Meunier et al., 2020). This is consistent with the finding that lianas with a DBH above $3 \mathrm{~cm}$ have a $95 \%$ probability or higher of being in the canopy, as observed by Kurzel et al. (2006) in multiple tropical forests including some investigated in this study (see below).

The optical thickness of each layer is computed from the total plant area index which is the sum of the wood and the clumpingcorrected leaf area index. In this study, we chose to neglect the 
TABLE 1 Leaf biochemical and canopy structural traits of the radiative transfer models used in this study, together with their prior distributions for lianas and trees as well as the posterior medians

\begin{tabular}{|c|c|c|c|c|c|c|}
\hline Abbreviation & Units & Description & PFT & Prior & Prior parameters & Posterior median $[95 \% \mathrm{CI}]^{\mathrm{b}}$ \\
\hline$C_{w}$ & $\mathrm{~cm}$ & Equivalent water thickness & $\begin{array}{l}\text { Liana } \\
\text { Tree }\end{array}$ & $\begin{array}{l}\text { Uniform } \\
\text { Uniform }\end{array}$ & $\begin{array}{l}a=0, b=0.1 \\
a=0, b=0.1\end{array}$ & $\begin{array}{l}0.0152\left[\begin{array}{lll}0.0151 & 0.152\end{array}\right] \\
0.0199[0.01970 .0200]\end{array}$ \\
\hline$N_{\text {layers }}$ & - & $\begin{array}{l}\text { Effective number of mesophyll } \\
\text { layers }\end{array}$ & $\begin{array}{l}\text { Liana } \\
\text { Tree }\end{array}$ & $\begin{array}{l}\text { Uniform } \\
\text { Uniform }\end{array}$ & $\begin{array}{l}a=1.01, b=5 \\
a=1.01, b=5\end{array}$ & 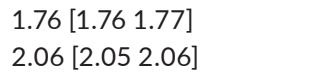 \\
\hline b1BI & $\mathrm{kg}$ plant $^{-1} \mathrm{~cm}^{-\mathrm{b} 2 \mathrm{Bl}}$ & Leaf biomass allometry intercept & $\begin{array}{l}\text { Liana } \\
\text { Tree }\end{array}$ & $\begin{array}{l}\text { Normal } \\
\text { Normal }\end{array}$ & $\begin{array}{l}a=0.049, b=0.010 \\
a=0.020, b=0.005\end{array}$ & $\begin{array}{l}0.049[0.0490 .049] \\
0.020[0.0200 .020]\end{array}$ \\
\hline$\Omega$ & - & Leaf clumping factor & $\begin{array}{l}\text { Liana } \\
\text { Tree }\end{array}$ & $\begin{array}{l}\text { Uniform } \\
\text { Uniform }\end{array}$ & $\begin{array}{l}a=0.4, b=1 \\
a=0.4, b=1\end{array}$ & 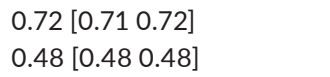 \\
\hline
\end{tabular}

Note: The prior parameters column provides the minimum (a) and maximum (b) values for the uniform distributions, or the mean (a) and the standard deviation (b) for the normal distributions.

${ }^{a}$ Equivalently referred to as $C_{m}$ (the units of which are $\mathrm{g} \mathrm{cm}^{-2}$ in PROSPECT-5).

${ }^{b}$ Posteriors from all studies/sites.

wood area given the relatively low contribution of wood to the plant area index (around 10\%, Olivas et al., 2013) and hence its limited impact on the radiative transfers (Viskari et al., 2019), the low number of observations of liana wood optical properties as well as to limit the number of parameters to calibrate. Therefore, the total plant area index of each cohort $\left(\varphi_{k}\right)$ was given solely by the leaf area index $\left(\mathrm{LAI}_{\mathrm{k}}\right)$. In ED2, each cohort crown occupies the full patch horizontal area (i.e. cohort leaves are distributed across the entire patch) but plant leaf area is corrected by a PFT-specific clumping factor $(\Omega) . \Omega$ is a purely horizontal clumping factor reducing the cohort light interception. In ED2, it is a constant that does not depend on the direction of the incident beam but is intended to compensate for the fact that radiative transfer is solved in $2 \mathrm{D}$ rather than in $3 \mathrm{D}$. $\Omega$ can vary between 0 and 1 and these numbers, respectively, represent the two extreme situations of a perfectly clumped (infinite LAl over an infinitesimally small area and null effective light interception, $\Omega=0$ ) and an evenly spread canopy (which captures the maximum amount of light per unit of leaf area, $\Omega=1$ ). This parameter is particularly relevant for lianas whose spatial distribution was shown to be clumped (Ledo \& Schnitzer, 2014; Schnitzer et al., 2012).

Cohort LAI $\left(\mathrm{LAI}_{\mathrm{k}}\right)$ is the product of the plant-level leaf biomass $\left(B_{\text {leaf, } \mathrm{k}}\right.$ which scales with diameter through another allometric equation), the plant density $\left(n_{k}\right)$ and the PFT-specific dry matter content (LMA). Therefore, the cohort plant effective area index $\varphi_{k}$ is given by:

$$
\Phi_{k}=\Omega \cdot \mathrm{LAI}_{\mathrm{k}}=\Omega \cdot\left(\frac{n_{\mathrm{k}} \cdot B_{\text {leaf }, \mathrm{k}}}{\mathrm{LMA}}\right)=\Omega \cdot\left(\frac{n_{\mathrm{k}} \cdot\left(b 1 B \mathrm{~B} \mid \mathrm{DBH}_{\mathrm{k}}^{b 2 B I}\right)}{\mathrm{LMA}}\right),
$$

with $b 1 B I$ and $b 2 B I$ the PFT-specific leaf biomass allometric intercept and slope coefficients, respectively. The relevant parameters are again further described in Table 1. The complete description of the radiative transfer model of ED2 can be found in Appendix A, in Longo et al. (2019a), or in Shiklomanov, Dietze, et al. (2020).

Recent work (Shiklomanov, Bond-Lamberty, et al., 2020; Shiklomanov, Dietze, et al., 2020) has refined the ED2 model's visible and solar infrared spectral resolution to nanometer-scale bands by coupling it with PROSPECT-5, which provides fine leaf spectral properties, so as to allow direct comparisons to multi- and hyperspectral data. This model version (a.k.a. ED-RTM) is instantaneous (the model runs for a single time step at user prescribed time and date) and allows computing radiative transfers within the canopy and the forest albedo down to the nanometer spectral resolution.

\subsection{Experimental workflow}

\subsection{1 | Literature meta-analysis}

We first collected published spectral data through an extensive literature search on science research engines (Web of Science and Google Scholar) with a combination of the following keywords: 'liana/woody vine', 'spectrum', 'reflectance', and 'canopy/leaf/ leaves'. We compiled records presenting leaf spectral measurements of both tropical lianas and trees, or canopy spectral measurements covering different levels of liana infestation in tropical forests. In the latter case, we only analysed the measurements with the lowest 
and highest liana coverages (hereafter referred to as liana-free and liana-infested stands) to capture the maximal differences in canopy spectra generated by liana infestation. We focused on data that overlapped the spectral region of interest: the visible and the solar infrared regions of the spectrum (400-2500 nm). Seven references emerged from our extensive search. These references could be categorized in three groups: studies that investigated leaf-level reflectance only (3), patch-level reflectance only (3), or both (1), see Table 2. In total, we compiled 1689 leaf spectra (1162 from lianas, 527 from trees) and eight patch-level average canopy spectra.

All five study sites were located in Latin America (Panama, Costa Rica, and Bolivia). The sites were tropical dry (SRNP, PNM, Gigante), wet (FTS) forests, or on the border of two climatic zones (SRNP), see Table 3. All leaf spectra were collected using field portable spectrometers on multiple leaf (3-15) samples from multiple liana (8-26) and tree (5-15) species. Stand-level spectra were obtained using different remote sensing techniques, including airborne spectrometers and satellite imaging (Table 3). Number of investigated tree crowns in crown/stand-level studies varied from a few (6 in Sánchez-Azofeifa \& Castro-Esau, 2006) to a large number (288 in Kalacska et al., 2007 and 554 in Marvin et al., 2016) while Foster et al. (2008) investigated a $771 \mathrm{~km}^{2}$ area with a $30 \times 30 \mathrm{~m}$ footprint.

Only two of the studies, Guzmán et al. (2018) and SanchezAzofeifa et al. (2009), made their raw data available. For those studies that did not provide their data, we digitized the spectra using the software Plot digitizer (v.2.6.8, http://plotdigitizer.sourceforge.net/) from the relevant figures. At the leaf level, two studies (out of the 4) reported spectral data only for parts of the visible and the near infrared (450-950 nm). All four studies that investigated patch-level reflectance differences with liana infestation included a large fraction of the visible and the near/short-wave infrared (Table 2). The significance of the liana impact was evaluated by testing whether the $95 \%$ confidence intervals of the difference of the spectra (liana vs. tree, liana-free vs. liana-infested) in a specific region included zero.

\subsection{2 | Model calibration}

To calibrate the leaf and the canopy spectra, we used the R package PEcAnRTM (https://github.com/PecanProject/pecan/tree/develop/ modules/rtm). This approach uses a Bayesian framework that provides the joint probability posterior distribution of the parameter set, thus capturing both the uncertainties and correlations among parameters. The independent prior distributions used in this study are included in Table 1. All but the priors of the leaf biomass allometric coefficients are uninformative. The residual variance $\sigma^{2}$ was assigned an uninformative inverse gamma prior as in Shiklomanov et al. (2016). We fit the respective models using the Differential Evolution with Snooker Update ('DEzs') Markov-Chain Monte Carlo (MCMC) sampling algorithm (ter Braak \& Vrugt, 2008) as implemented in the R package BayesianTools (Hartig et al., 2019). For each inversion, we ran five independent chains until convergence with a burn-in of 50,000 and 100,000 iterations for leaf and canopy scales, 
TABLE 3 Basic information related to the sites included in the meta-analysis and the instruments used to obtain the leaf- and stand-level spectra

\begin{tabular}{|c|c|c|c|c|c|}
\hline Study site & Location (Lat, Lon) & Forest type & $\mathrm{MAP}(\mathrm{mm})$ & MAT $\left({ }^{\circ} \mathrm{C}\right)$ & Instrument (study short name) \\
\hline PNM, Panama & $8.99^{\circ} \mathrm{N} ; 79.55^{\circ} \mathrm{W}$ & Tropical dry, secondary forest & 1750 & 25 & $\begin{array}{l}\text { - UniSpec Spectral Analysis System } \\
\text { (Castro PNM, Sanchez PNM) } \\
\text { - ASD Fieldspec spectrometer } \\
\text { (Kalacska, Sanchez) } \\
\text { - Hyperspectral Digital Imagery } \\
\text { Collection Experiment (Kalacska) }\end{array}$ \\
\hline FTS, Panama & $9.28^{\circ} \mathrm{N} ; 79.98^{\circ} \mathrm{W}$ & Tropical old-growth wet forest & 3300 & 26.5 & UniSpec Spectral Analysis System \\
\hline Gigante, Panama & $9.1^{\circ} \mathrm{N} ; 79.8^{\circ} \mathrm{W}$ & $\begin{array}{l}\text { Seasonally dry, secondary } \\
\text { tropical moist forest }\end{array}$ & 2400 & 25.5 & $\begin{array}{l}\text { Airborne Taxonomic Mapping System } \\
\text { (AToMS) visible-to-short-wave } \\
\text { infrared imaging spectrometer }\end{array}$ \\
\hline NKMNP, Bolivia & $13.93^{\circ} \mathrm{S} ; 61.11^{\circ} \mathrm{W}$ & Tropical wet-dry forest & 1450 & 25.5 & EO-1 Hyperion \\
\hline
\end{tabular}

respectively. We evaluated the quality of the model calibration at the leaf level and the stand level by comparing modelled and observed reflectance values and by computing several error statistical metrics (the root mean square error [RMSE], bias [BIAS], and bias-corrected RMSE (SEPC) averaged across the visible [400-700 nm], the near infrared [700-1400 nm], and the short-wave infrared [1500-2500 nm] regions of the spectrum), see Supplementary Appendix B for more details.

\section{Estimating leaf optical traits from leaf spectra}

For all studies for which we had leaf-level reflectance data, we estimated all five PROSPECT-5 leaf-level parameters (Figure 1, step 1), through the exact same spectral inversion procedure described by Shiklomanov et al. (2016). We repeated the PROSPECT-5 inversion for each site/study and each PFT. When raw data were available, we fitted PROSPECT-5 parameters individually to each plant species. After calibration, we aggregated all study/site posteriors to the PFT level (liana or tree) by attributing a similar weight to each of them.

\section{Refining leaf optical trait estimates from canopy spectra}

For the studies for which patch-level reflectance data were available, we followed Shiklomanov, Dietze, et al. (2020) to carry out a similar calibration scheme using ED-RTM. The calibrated model parameters include the leaf parameters of PROSPECT-5 plus the leaf allometric coefficients, the leaf orientation, and the clumping factor (Figure 1, step 2). We used the aggregated posterior distributions from step 1 as informative prior distributions for the PROSPECT-5 parameters. The priors of leaf biomass allocation coefficients were informed by an independent literature review (Falster et al., 2015; Gehring et al., 2004; Gerwing \& Farias, 2000; Putz, 1983; Schnitzer et al., 2006; Smith-Martin et al., 2020) through which we collected all leaf biomass allometric data comparing trees and lianas (Meunier et al., 2020). These data originate from multiple biomes (tropical wet and dry forests) in multiple countries (Brazil, Venezuela, Cambodia, French Guiana, Paraguay, Costa Rica). Informed priors of leaf biomass allometric coefficients were built based on the fit of the allometric equation of ED2 to these data using the PEcAn.allometry package (https://github.com/pecanproject/pecan/tree/develop/ modules/allometry).

In ED-RTM, we simulated two competing PFTs, respectively, accounting for lianas and tropical trees. For the purpose of the canopy inversion, we assumed that all trees at a given site shared the same spectral property distributions, and all lianas likewise shared another set of spectral property distributions. As for the leaf-level studies, we performed a separate calibration for every single study and site (Table 2) and aggregated the posterior distributions giving the same weight to every calibration. This approach allowed a better fit for every leaf canopy spectra while accounting for the inter-site variability of liana and tree properties.

When both leaf- and patch-level reflectance data were available (Kalacska et al., 2007), we performed a similar two-step calibration. Yet, as compared to the other stand-level calibrations, we only used the site-specific PROSPECT-5 posterior distributions as priors in the second step to derive canopy structural traits. To improve the vertical resolution of the radiative transfer, we prevented cohort fusion during the calibration of ED-RTM. Therefore, every single plant cohort (liana or tree) consisted of a single individual (see Supplementary Figure F5).

\subsubsection{Evaluating the impacts of liana-specific traits}

To determine the impact of lianas on forest radiative transfers and biogeochemical cycles, posterior distributions of leaf and canopy traits of both PFTs resulting from the two-step calibrations were used to parameterize the full version of the ED2.2 vegetation model (Figure 1, step 3). We generated two ensembles of 100 simulations each in which liana radiative traits were sampled either from the liana ('liana' runs) or the tree ('reference' runs) posterior distributions. Liana leaf biomass allometric parameters (b1BI and b2BI), dry matter (LMA), and all tree parameters were systematically sampled from their proper PFT distributions. This allowed us to evaluate the impact of the leaf radiative parameters (the visible and infrared transmissivity and reflectivity coefficients $-\tau_{\mathrm{vis}}, \rho_{\mathrm{vis}}, \tau_{\mathrm{IR}}$, and $\rho_{\mathrm{IR}}-$ leaf 
angle $\omega$ and leaf clumping $\Omega$ ) on forest functioning while conserving identical ecosystem LAI.

We ran the model on the 50 ha plot of $\mathrm{BCl}$, Panama, which is an old-growth seasonally moist lowland tropical forest. Previous ED2 simulations demonstrated the model's capacity to reproduce land surface fluxes (di Porcia e Brugnera et al., 2019) and several features of the liana-tree competition there (Meunier et al., 2020). $\mathrm{BCl}$ is characterized by an average (years 2003-2016) annual rainfall of about $2640 \mathrm{~mm}$ (Detto et al., 2018) and a well-marked 4-month dry season (total rainfall between late-December and mid-April is $175 \mathrm{~mm}$ on average). We used the 2007 liana inventory and the tree inventory that was carried out immediately afterwards (2010) to prescribe the vegetation initial conditions. These censuses included all individuals whose DBH is larger than $1 \mathrm{~cm}$ in the $500 \mathrm{~m} \times 1000 \mathrm{~m}$ plot (Condit et al., 2019; Schnitzer et al., 2012). The 50 ha site was divided into an initial number of 1250 patches in a regular grid of $20 \times 20 \mathrm{~m}$. Initial liana density averaged 1429 individuals per hectare and varied significantly from liana-free to liana-infested patches (liana density standard deviation was 1013 individuals per hectare). Model simulations were run for 5 years starting in 2007 using the meteorological drivers locally available (Powell et al., 2017, 2018). We also used the observed carbon and energy land fluxes obtained with the eddy-covariance method to benchmark the modelled productivity, evapotranspiration, and albedo (Pau et al., 2018). The other model parameters for the liana and the tree PFTs are exhaustively described in Meunier et al. (2020) and in Longo et al. (2019a).

We analysed the differences between model outputs with a special focus on the energy budget and the carbon cycle. These differences were evaluated as both absolute ('liana' runs minus 'reference' runs) and relative (absolute differences normalized by the 'reference' runs) changes.

In addition, we also simulated the instantaneous radiative transfers at the same site using ED-RTM and finer patch and cohort resolutions (the regular grid of $20 \times 20 \mathrm{~m}$ kept unfused and every single plant as a 'cohort') and the posterior median of every single parameter. Again, liana optical traits were either assigned liana- or tree-specific values. We then related the changes of forest albedo and understorey light (defined as the downward radiation below the shortest plant or the radiation reaching the ground) to the degree of liana infestation by fitting the coefficients $y_{\max }$ and $b$ of the following equation using the 'nlsLM' function of the minpack.Im $R$ package (Elzhov et al., 2016):

$$
y=y_{\max }[1-\exp (-b \cdot x)]
$$

where $y$ is the response (forest albedo in the visible and in the infrared, or the understorey light) and $x$ is the contribution of lianas to the ecosystem LAI.

Finally, we ran uncertainty analyses of every single model used in this study (PROSPECT-5, ED-RTM, and ED2.2) with PEcAn (LeBauer et al., 2013). In short, PEcAn combines the uncertainty of model parameters after calibration with a univariate sensitivity analysis to estimate the contribution of each parameter to the overall predictive uncertainty, see Supplementary Appendix C for details. All intervals presented in this study are $95 \%$ confidence intervals $(\mathrm{Cl})$.

\section{3 | Independent evaluation of model outputs}

We validated the main model outputs using independent datasets. In particular, we evaluated the impacts of lianas on forest albedo using WorldView-3 images and on light penetration through the canopy using GatorEye UAV-LiDAR.

\subsubsection{WorldView-3}

To validate the changes in albedo due to liana infestation, we obtained a WorldView-3 image of central Panama acquired on 24 March 2016. The image has a $2 \mathrm{~m}$ spatial resolution, 2.6 degree mean off-nadir view, 67.9 degree mean sun elevation, with $11.5 \%$ cloud cover. The image was corrected to surface reflectance using Fast Line-of-sight Atmospheric Analysis (Cooley et al., 2002; http:// www.harrisgeospatial.com). The scene included a cloud-free area of georeferenced tree crowns on Gigante Peninsula (south of $\mathrm{BCl}$ ) where liana infestation of 544 trees was tallied from the ground with binoculars using the liana crown occupancy index (COI, see Marvin et al., 2016). This resulted in over 8000 pixels with ground referenced infestation scores. To investigate the effect of liana infestation on forest albedo, we compared the reflectance of crowns with extreme levels of liana occupancy $(0.05<\mathrm{COI}<0.25 \mathrm{vs}$. COI $>0.75)$ across six spectral bands (from blue to NIR-2), using independent nonparametric Mann-Whitney $U$ tests for each band and the COI category as treatment. The two liana-infestation levels resulted in large numbers of samples in both groups (5866 and 387 for low and high COI, respectively, totalling 2.35 and $0.15 \mathrm{ha}$ ).

\subsection{2 | UAV LiDAR}

To evaluate whether liana-rich stands differed in light extinction, GatorEye UAV-borne LiDAR data obtained on $\mathrm{BCl}$ in February 2019 were combined with a local dataset of COI. Tree crowns were mapped for a total of 2133 individuals. Each crown was manually delineated from UAV-derived orthomosaic of the 50 ha plot of $\mathrm{BCl}$, as described in Park et al. (2019). Each delineated tree crown was then visited in the field and a liana crown occupancy index was recorded from the ground. UAV-borne LiDAR data were collected at $905 \mathrm{~nm}$, using the GatorEye Unmanned Flying Laboratory (see www.Gator Eye.org for detailed description and data access) at the 50 ha plot on Barro Colorado Island. GatorEye Gen 1 uses a DJ Matrice 600 Pro hexacopter, equipped with a Velodyne VLP-16 puck lite sensor with manufacturer calibrated intensity, as well as hyperspectral and visual sensors not used in this study. Flights were conducted at $55 \mathrm{~m}$ aboveground level (AGL), with an $80 \%$ sidelap, and at an average speed of $40 \mathrm{~km} / \mathrm{h}$. The LiDAR spatial footprint has a diameter of 
3-9 $\mathrm{cm}$ at 10-30 $\mathrm{m}$ distance, resulting in an average canopy height (30 m AGL) footprint of $7.5 \mathrm{~cm}$ diameter.

We compared the manufacturer calibrated intensity, as measured by the LiDAR, between liana-free and highly infested trees, as reflected by the individual tree COI. LiDAR intensity varies with surface reflectivity, leaf density in the canopy, and distance. Yet, as the distance from sensor to tree canopies was approximately the same across the entire plot and we average thousands of returns per quadrant, intensity is expected to provide a good estimation of relative differences in reflectivity and leaf density among the sample areas. In other words, LiDAR intensity should differ between liana-free and liana-infested tree crowns only if the projected leaf area and/or leaf traits within the beam footprint differs. Higher return rates (as indicated by a larger intensity) and hence larger light extinction coefficient could therefore be caused by more uniform leaf distribution (smaller clumping), more horizontal leaves, larger leaf reflectivity, or a combination of these three factors.

We compared the relative (scaled between 0 and 1) LiDAR intensity of crowns with extreme levels of liana occupancy (COI $<0.25$ vs. $\mathrm{COI}>0.75$ ), using a nonparametric Mann-Whitney $U$ test with the liana infestation level as treatment. These two categories resulted in a large number of individual crowns in both groups (1486 and 417 for low and high $\mathrm{COI}$, respectively).

\section{3 | RESULTS}

\section{1 | Leaf biochemical and canopy structural trait differences between growth forms}

Most collected leaf-level studies agreed on the direction of the discrepancies between liana and tree leaf spectra (Supplementary Appendix D). Five out of the six leaf-level collected references indicated that liana leaves were significantly more reflective than tree leaves in the visible (especially in the green peak) until the red edge (680-700 nm). The sixth study, Sanchez (FTS), showed no differences, on average, between liana and tree leaves in the visible region of the spectrum. In the near infrared (700-1400 nm), all studies agreed on a significantly lower reflectance of liana leaves at least until $950 \mathrm{~nm}$ (the upper limit of spectral measurements in Castro (FTS), Castro (PNM) and Guzmán, see Table 2). In the short-wave infrared (1500-2500 nm), liana leaves were variably characterized as having on average higher (Kalacska), lower (Sanchez, PNM), or the same (Sanchez, FTS) reflectance as tree leaves. At the canopy level, all four studies found higher reflectances for liana-infested patches in the visible and short-wave infrared, and all but Kalacska also found higher reflectance in the near infrared (Supplementary Figure C2 and Table C1).

Both PROSPECT-5 and ED-RTM were able to accurately reproduce observed leaf and canopy spectra from individual studies across the whole spectrum (Supplementary Appendix E). At the leaf level, $r^{2}$ of observed vs modelled leaf reflectance values grouped by wavelength reached on average 0.91 , with no values lower than
0.75 (Supplementary Figure E3). Overall simulated leaf spectra reproduced discrepancies between liana and tree leaf reflectance values both in the visible and in the infrared (Supplementary Table D1). Similarly, at the canopy level, model performance after model calibration was good with a mean $r^{2}$ of .93 for observed vs. simulated reflectance values across all wavelengths, and none lower than 0.71 (Supplementary Figure E3). Observations of reflectance discrepancies between forest stands with different infestation levels were also well reproduced by the best set of parameters, both in the visible and in the infrared (Supplementary Table E1).

Liana and tree parameter distributions had large variances and therefore largely overlapped across and within studies. However, we did observe significant differences in central tendencies. All calibrations predicted lower chlorophyll contents in liana leaves as compared to tropical tree leaves (Supplementary Figure F1). The difference between chlorophyll content in liana and tree leaves reached $-11.1 \mu \mathrm{g} \mathrm{cm}^{-2}$ when averaging all studies (Table 1). Similarly, all studies/sites parameter calibrations predicted lower carotenoid contents in tropical liana leaves (on average $-4.7 \mu \mathrm{g} \mathrm{cm}^{-2}$ ) and a smaller number of stacked layers $(-0.3)$ corresponding to thinner leaves in liana species. The calibrations predicted either no differences or smaller dry matter content in liana leaves (LMA decreased on average by $-0.022 \mathrm{~kg} \mathrm{~m}^{-2}$ for liana leaves). In addition, significant differences of water layer thickness $C_{w}$ emerged in all studies/sites but one (Castro, PNM), leading to a mean water content increase of $+3.7 \%$ in liana leaves (once combined with LMA). Altogether, those traits resulted in significant increases in liana leaf transmittance $(+0.02$ in the visible and +0.01 in the solar infrared) and reflectance in the visible $(+0.004)$, as well as a significant decline in liana leaf reflectance in the near infrared (-0.01), see Figure 2a (as well as Supplementary Figure F2).

Leaf allometric intercepts already differed between growth forms according to the literature meta-analysis (Table 1) and were further discriminated by model calibration (Supplementary Figure F1). The slope of the leaf biomass allometric equation was slightly larger for lianas, before and after calibration (Table 1 and Supplementary Figure E1). Together, these leaf biomass allometric coefficients drew the picture of a larger carbon allocation to leaf biomass by lianas than by trees of similar DBH across all sizes (Figure $2 b$ ). All four studies that measured the impact of liana coverage on canopy reflectance revealed, after calibration, more horizontal leaves for lianas than for trees (Supplementary Figure F1), resulting in flatter leaf angles for lianas (Figure 2c). In addition, lianas were systematically predicted to have larger clumping factors (i.e. larger light interception per unit of leaf area) as compared to trees (Figure 2c; Table 2).

\subsection{Impact of liana traits on forest biogeochemical cycles}

The leaf biochemical and canopy structural traits of lianas deeply impacted the energy balance and the carbon cycle of the forest, as simulated by ED2 (Figure 3). Liana leaf traits increased in forest albedo: 

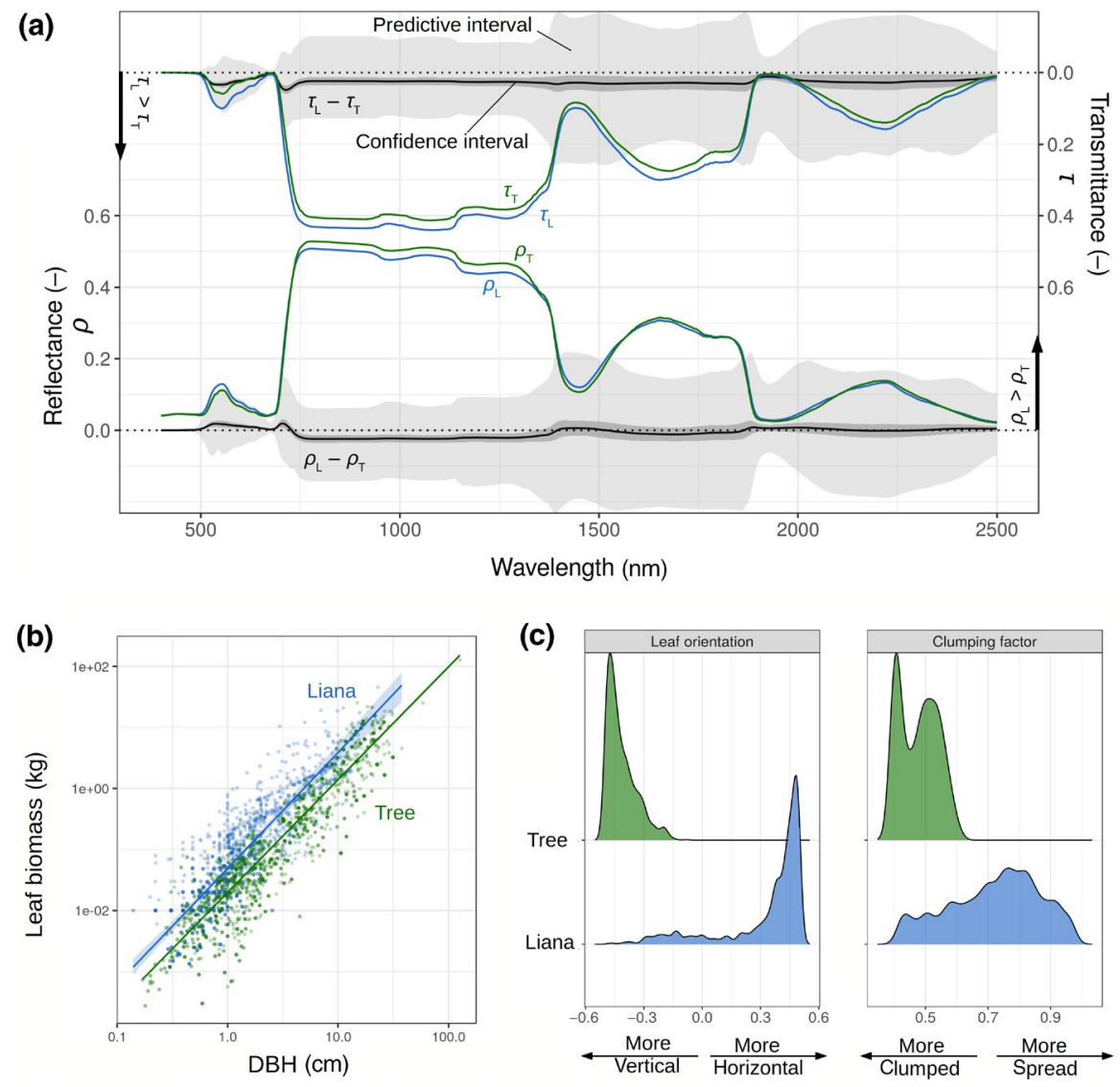

FIGURE 2 Liana (blue) and tree (green) optical and canopy structural parameters, resulting from the leaf and canopy spectral calibrations. In (a), liana and tree mean reflectance ( $\rho_{\mathrm{L}}$ and $\rho_{\mathrm{T}}$, respectively) and transmittance ( $\tau_{\mathrm{L}}$ and $\tau_{\mathrm{T}}$, respectively) are plotted together with their differences $\left(\rho_{\mathrm{L}}-\rho_{\mathrm{T}}\right.$ and $\left.\tau_{\mathrm{L}}-\tau_{\mathrm{T}}\right)$ at the nanometer resolution. The light and dark grey envelopes, respectively, represent the $95 \%$ predictive and confidence intervals of the differences (liana - tree) resulting from 500 liana and tree PROSPECT- 5 simulations sampled from the growth-form-specific posterior distributions. In (b), liana and tree mean (solid lines) allometric allocations to leaf biomass together with their confidence intervals (shaded envelopes) are superimposed on the data that served to constrain the prior distributions (collected through an independent meta-analysis). In (c), we compare the posterior distribution densities of liana and tree leaf orientation (left) and clumping factor (right), resulting from the calibration of the canopy spectra

over the 5 years of simulation, the energy reflected back to the atmosphere increased on average by $17.1 \%$ in the PAR mainly because of the higher reflectivity of liana leaves in the visible region and by $11.7 \%$ in the infrared driven by more horizontal angle distribution of liana leaves and larger clumping factors (Supplementary Appendix C). This corresponded to an additional $3.6 \mathrm{~W} \mathrm{~m}^{-2}$ of energy that was sent back to the atmosphere (Supplementary Figure F3). A larger fraction of the penetrating forest solar radiation was absorbed by the canopy in the runs where liana-specific traits were attributed to lianas (i.e. 'liana' runs), with an average increase by $7.4 \%$ and $7.8 \%$, respectively, in the visible and the solar infrared (or $+8.2 \mathrm{~W} \mathrm{~m}^{-2}$ in total). Hence, fewer photons reached the ground resulting in darker understories $\left(-11.8 \mathrm{~W} \mathrm{~m}^{-2}\right.$ as summed up over the visible and the infrared, corresponding to a $22 \%$ decrease) and slightly cooler soils (on average $-0.5^{\circ} \mathrm{C}$ in the topsoil over the 5 years of simulations).

The ecosystem-level increase in albedo and decrease in understorey light were mainly driven by the liana-rich patches on $\mathrm{BCI}$ (Figure 4). In liana-infested patches, the increase in albedo reached up to 0.05 in the infrared and 0.002 in the visible, while light reaching the ground could be reduced by more than $50 \%$. On $\mathrm{BCl}$, the liana optical traits increased the short-wave albedo by +0.015 on average, which improved the fitness of the simulated outgoing short-wave radiation when compared to the fluxtower data: RMSE of the modelled versus observed reflected short-wave radiation decreased from 2.2 to $1.7 \mathrm{~W} \mathrm{~m}^{-2}$ once liana traits were accounted for (Supplementary Figure F4).

The larger values of the leaf orientation parameter for lianas (i.e. more horizontal leaf distribution) and clumping parameters (i.e. more evenly distributed leaves) made lianas very efficient at light interception (intercepted PAR by lianas increased by $48 \%$ on average when liana optical traits were accounted for). This translated into a large increase in both gross and net productivity of the liana PFT $(+27.2 \%$ and $+30.5 \%$, respectively) while trees were negatively impacted by those liana-specific traits (tree GPP and NPP decreased by $19.1 \%$ and $23.8 \%$, respectively). Tree productivity decline was not compensated by liana gains: compared to the reference runs, ecosystem gross and net productivity decreased in the 'liana' runs by $6.8 \%$ and $8.2 \%$, respectively. Combined with a slight increase in heterotrophic respiration, the net ecosystem productivity was reduced by 
(a) Energy cycle

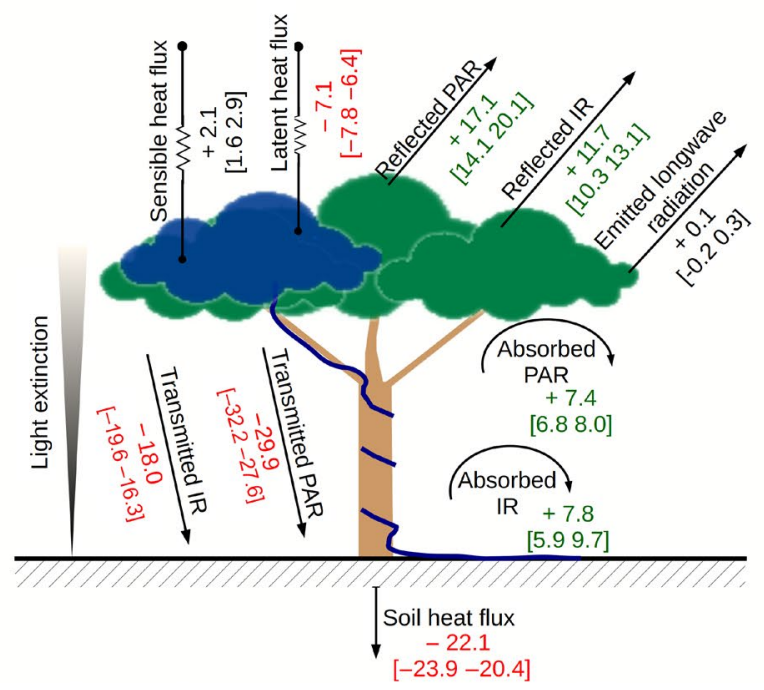

(b) Carbon cycle

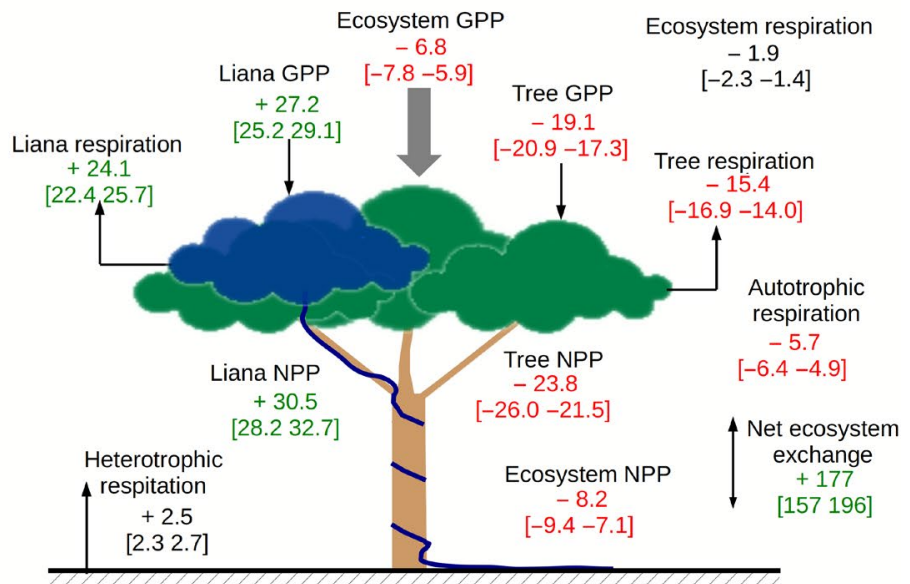

FIGURE 3 Mean relative changes (\%) together with their confident intervals of the energy (a) and carbon (b) cycle fluxes resulting from the implementation of the liana radiative model parameters. These changes are relative to the fluxes simulated when lianas were assumed to have the same radiative and structural parameters as trees. Fluxes are coloured in red (respectively green) when the mean relative changes of the corresponding fluxes are lower than $-5 \%$ (respectively higher than $+5 \%$ )

1.6 $\mathrm{T}_{\mathrm{C}} \mathrm{ha}^{-1}$ year $^{-1}$ when liana-specific optical traits were accounted for. After 5 years of simulation, ecosystem AGB increased more slowly in the 'liana' runs as compared to the 'reference' ones (reduction of $4 \mathrm{~T}_{\mathrm{C}}$ ha $^{-1}$ ): tree $\mathrm{AGB}$ increase was reduced by $4.5 \mathrm{~T}_{\mathrm{C}} \mathrm{ha}^{-1}$ while liana AGB was enhanced by $0.5 \mathrm{~T}_{C}$ ha $^{-1}(+11 \%)$. The simulated seasonal cycle of latent heat and gross primary productivity were both slightly improved when liana-specific optical traits were taken into account (Supplementary Figure F4).

\subsection{Independent evaluation of model outputs}

WorldView-3 images confirmed that liana-infested canopies were characterized by significantly higher albedos in the near infrared $(+0.051$ on average, $p<2 \mathrm{e}-16)$ and in the green peak $(+0.002$, $p=.004)$, see Figure $5 a$. These numbers matched the asymptotes predicted by the radiative transfer model under extreme levels of liana infestation (Figure 4).

We could not validate individually the differences in canopy clumping and leaf angle of liana species but the GatorEye UAVLiDAR confirmed the more important canopy closure of liana-rich crowns resulting from the combination of such features (Figure $5 \mathrm{~b}$ ). Larger COI were associated with greater LiDAR intensities $(p<2 \mathrm{e}$ 16), which indicates that there is a greater and more reflective leaf area within the footprint of the laser. As liana leaves tend to have lower reflectance around $900 \mathrm{~nm}$ (Figure 2a), the greater return intensity of infested crowns is likely caused by a higher LAI of more horizontal leaves, more evenly spread canopies, or both, which is consistent with the posterior distribution discrepancies between growth forms (Figure 2c; Table 1).

\section{DISCUSSION}

\subsection{Ecosystem-level impacts of lianas}

This study is the first to comprehensively investigate the role of lianas on the energy budget and radiative transfer of tropical forests. According to our model simulations, lianas significantly alter the forest energy cycle (Figure 3a). As hypothesized, liana optical traits are responsible for an increase in albedo and a decrease in light penetration through the canopy, especially in the heavily infested forest patches (Figure 4). By increasing the light competition, liana traits also reduce tree carbon assimilation and the positive shift in liana productivity does not compensate for the tree drop, resulting in an overall decline of the ecosystem productivity (Figure 3b). Since liana abundance seems to be increasing in the Neotropics (Phillips, 2002; Schnitzer \& Bongers, 2011), these findings might translate into important changes in the functioning of those tropical forests. If the liana impacts detected in this study (forest understorey darkening and reduced ecosystem productivity) were confirmed in a larger number of sites, liana proliferation could translate into a global weakening of forest carbon sink strength.

Yet, we note that these negative impacts could be mediated or even counterbalanced by other liana-induced effects. By reducing the solar radiation reaching the ecosystem (especially in the infrared), overtopping lianas could act as a protective mantle isolating tree leaves from rising temperatures and the resulting exacerbated evaporative demand expected in the tropics (Konapala et al., 2020). Lianas could also help maintain more appropriate soil conditions (temperatures and water content) and hence protect soil carbon reservoirs as well as the critical biota living therein, which are currently 

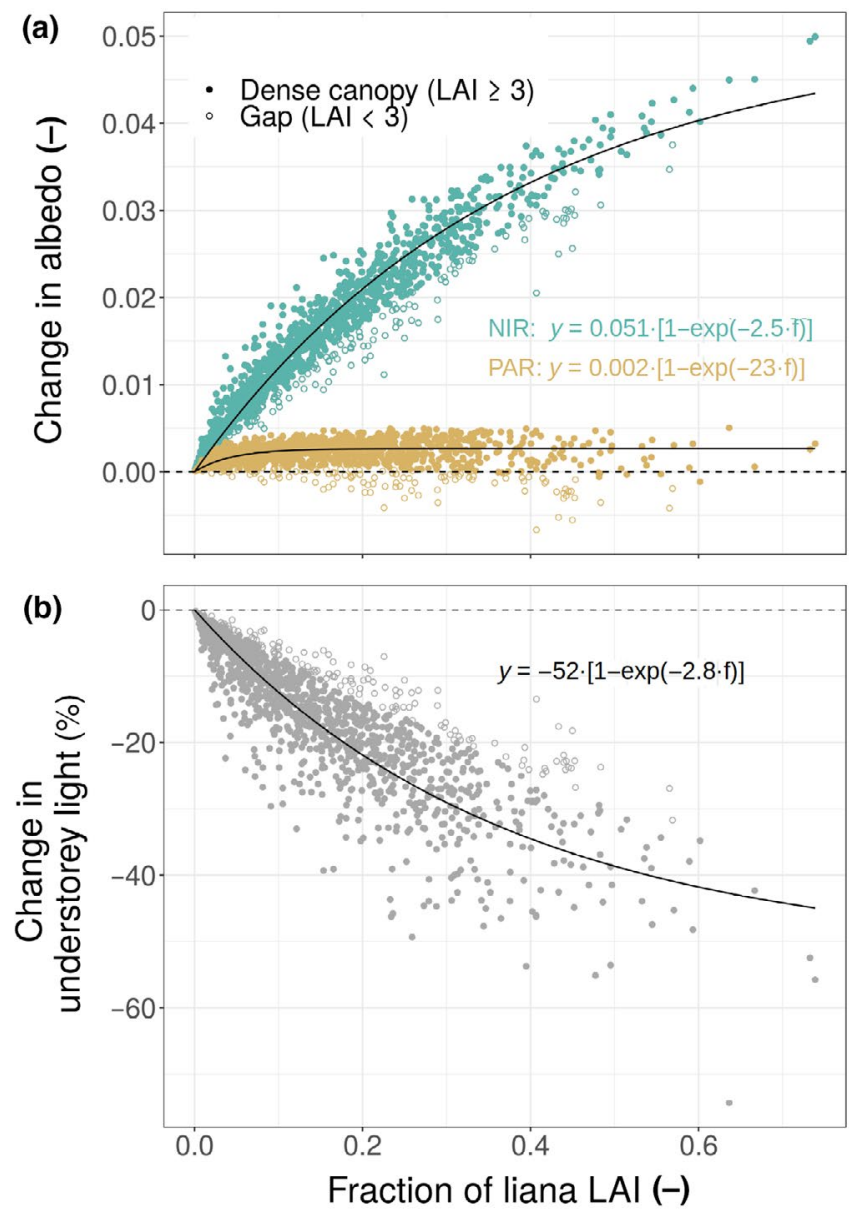

FIGURE 4 Changes in albedo (a) and understorey light availability (b) as a function of the liana infestation, expressed here as the contribution of lianas to the ecosystem LAI. In (a), the impact was split into changes of PAR (yellow) and infrared (green) albedo, and in both subplots we distinguished dense vegetation patches ( $\mathrm{LAI} \geq 3$, closed symbols) and gaps ( $\mathrm{LAI}<3$, open symbols). Fits were applied to all data points (dense canopies and gaps together)

threatened by increasing soil temperatures (Mitchard, 2018). Finally, as degraded forests with more open canopy (and hence warmer understorey temperatures) are more flammable during mild/moderate droughts (Longo et al., 2020), the susceptibility to fires could also be reduced in liana-infested patches. Those potential positive effects of lianas need to be confirmed in future field and modelling studies.

Finally, our results suggest that the increase in liana abundance observed in the Neotropics (Phillips, 2002; Schnitzer \& Bongers, 2011) could be driven by the higher efficiency of lianas to intercept light combined with an overall decrease in cloudiness in the area (Arias et al., 2011; Fu et al., 2013). The liana-specific leaf and canopy traits identified in this study coupled to earlier observations of efficient hydraulic architectures (Chen et al., 2015, 2017; van der Sande et al., 2013) could indeed allow lianas to thrive through light-rich extended dry seasons and more frequent drought stress episodes, during which lianas have been shown to grow more than co-occurring trees (Schnitzer, 2005; Schnitzer \& van der Heijden, 2019).

\subsection{Study limitations}

The most important limitation of this study is the representativity of the data that we collected through our meta-analysis. Although we were able to compile a large number of liana leaf spectra ( $>1000)$, they all originated from Latin America. Most of them were from a single country (Panama) and from a very limited number of sites (3, see Table 2). The stand-level spectra that we collected also all came from a limited number of sites in the Neotropics (3, see Table 2) and their number was more limited as we could not obtain any raw data. Yet, the meta-analysis performed in this study was comprehensive and therefore the limited spatial distribution of the sites reflects the absence of data elsewhere. The upscaling/extrapolation of our findings to all tropical forests globally should therefore be performed with caution until additional liana spectra with more diverse origins have been collected and assimilated into the model. However, the potential important changes induced by lianas highlighted in this study should motivate further study on the short term in other tropical sites. In particular, leaf sampling in regions where lianas do not seem to be increasing (Bongers et al., 2020) could lead to a breakthrough for unravelling the mechanisms driving liana proliferation. In addition, a publication bias could not be ruled out in our meta-analysis as the number of collected studies was too small to calculate publication bias diagnostics such as funnel plots (Koricheva et al., 2013). Yet, the inversion of the leaf spectra led to a pattern (lianas grow cheaper, thinner leaves, with lower pigment concentration and lower leaf mass per area), which is consistent with multiple local observations (Castro-Esau et al., 2004; Sánchez-Azofeifa et al., 2009), the pan-tropical analysis of Asner and Martin (2012) who found smaller LMA and no differences or lower area-based light capture-growth chemical concentrations in liana leaves, and higher leaf turnover rates in liana-rich plots (van der Heijden et al., 2015). The main findings on liana structural and leaf properties (differences in leaf angle, clumping, and distributions) were also confirmed by ground truth validation based on canopy and leaf direct observations (Visser et al., 2021).

Furthermore, the ED2 (and ED-RTM) representation of infinitely thin crowns covering the entire patch and overtopping lianas probably contributes substantially to the large impact of lianas on forest albedo, and energy balance. These model structural uncertainties, even if they have been shown to be less critical than model parameter uncertainties for ED2 (Shiklomanov, Bond-Lamberty, et al., 2020) and were minimized in the model and in our analyses (clumping factor, cohort size limit), need to be accounted for in the future, by investigating the impact of plant crown size (Dietze et al., 2008) and crown depth representation (Fisher et al., 2010, 2018) in the canopy radiation model. Yet, the effects of liana abundance on albedo predicted by the model are consistent with those observed in the original stand-level spectral data, as well as the independent Worldview-3 multispectral and GatorEye UAV-LiDAR data, suggesting that the impacts of any structural biases are either minor or related to compensating errors that are not apparent in any of our diagnostics. Additional independent field data on the leaf angle 

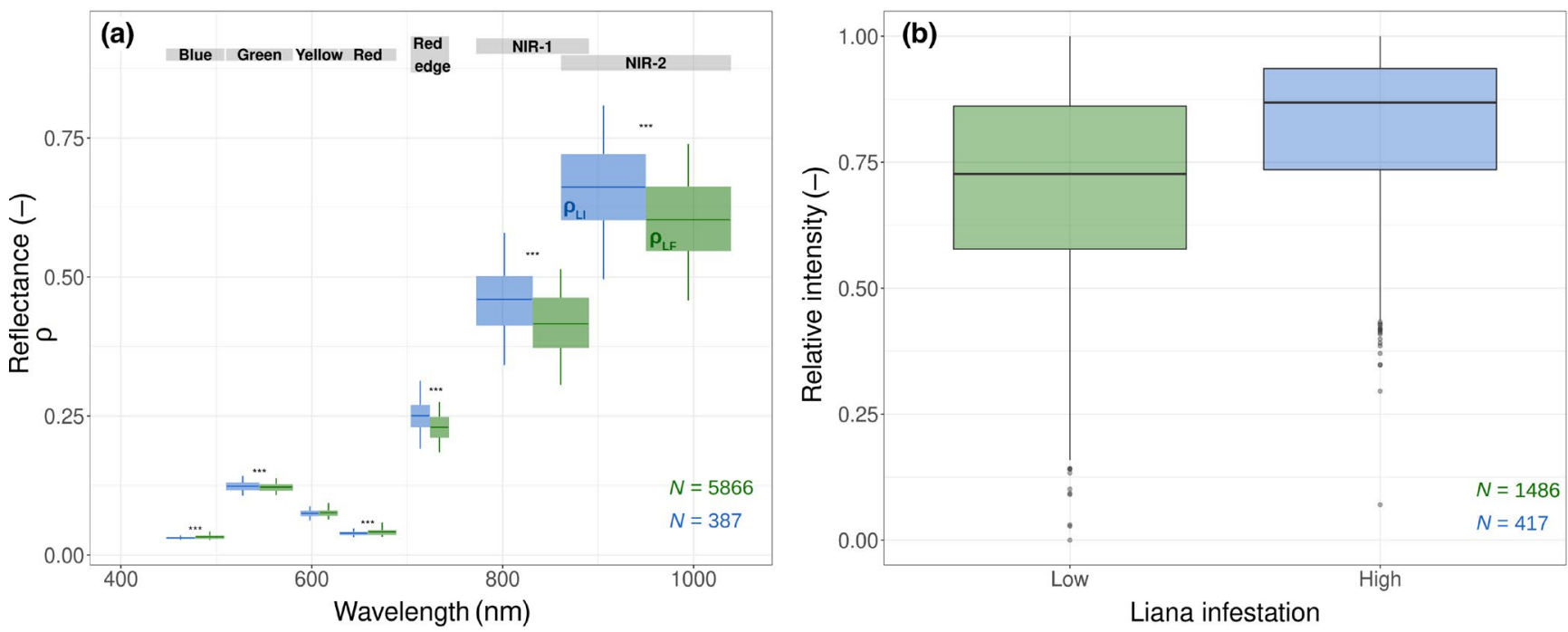

FIGURE 5 Independent evaluation of the liana impacts on forest albedo (a) and light penetration (b). In (a), we compare the mean reflectance of liana-free (green, $\rho_{\mathrm{LF}}$ ) and liana-infested (blue, $\rho_{\mathrm{LI}}$ ) canopies. Boxplot widths correspond to half the size of the bands in the Worldview-3 images (indicated above). In (b), the relative intensity detected by UAV-borne LiDAR measurements is compared between low and high liana infestation. Higher values indicate higher return rates (and hence smaller light penetration into the canopy)

distribution and leaf clumping would help rule out such compensating errors, but it is worth noting that the current parameter estimates are, at least qualitatively, consistent with our understanding of liana canopy morphology and liana ecology, more broadly. Our results are indeed in agreement with experimental observations of a steep increase in forest net productivity once lianas are removed (van der Heijden et al., 2015) and further suggest that light competition is the critical driver of competition, as expected in dense tropical ecosystems (Bongers \& Sterck, 1998; Poorter et al., 2003). The strong reduction in light penetration induced by liana infestation was also evidenced in several liana removal experiments (Estrada-Villegas \& Schnitzer, 2018). Finally, in the absence of better information on tree optical traits variability and to avoid overfitting issues, we chose to calibrate the ED-RTM model assuming that all trees shared the same distribution of spectral properties in each site/study. This is currently what is assumed in the ED2 model (Longo et al., 2019a). Yet, trees exhibit large variability of optical spectra (Visser et al., 2021), and therefore this assumption is an important limitation of our study and should be taken into account in future sensitivity and field analyses.

\section{3 | Perspectives}

Our study opens new avenues to estimate the contribution of lianas on seasonal and interannual changes of forest albedo observed at large scales (Ahlström et al., 2017; Asner \& Alencar, 2010; Brienen et al., 2015). Since liana leaf biomass, relative to trees, can increase during the dry season (Avalos \& Mulkey, 1999; Schnitzer, 2005) and is expected to soar on the longer term (Phillips, 2002; Schnitzer \& Bongers, 2011), liana-induced shifts in albedo could be visible both at short and long timescales. Vegetation model simulations could help estimate the future impact of lianas on tropical forest albedo and functioning, more broadly under contrasting global scenarios.

Our results (Figure 4 in particular) also suggest that multispectral sensors (alone or in combination with LiDAR) should be able to detect forest stands characterized by high liana coverage. In a related study, Visser et al. (2021) demonstrate that lianas can be detected from remote sensing data. They also show how radiative transfer models can assist in the estimation of liana traits from hyperspectral images of liana-infested canopies just as it is currently achieved for trees (Gong et al., 2003; Meroni et al., 2004; Serbin et al., 2015). This is because liana-rich patches are similarly sensitive to liana parameters, just like liana-free forest stands are to tropical tree parameters (Supplementary Appendix C). Together this study and the one of Visser et al. (2021) who compiled a larger and better distributed library of liana spectra suggest that liana infestation changes could be detected at large scale with remote sensing and that our findings could be valid in a larger number of sites than those investigated here.

This study is a first step towards a comprehensive understanding and quantification of the impact of lianas on tropical forests. The current belief is that the increase in liana abundance driven by climate change and exacerbated by anthropogenic pressures could accelerate global warming by decreasing the carbon sequestration capacity of ecosystems (Reis et al., 2020; Schnitzer \& Bongers, 2011; van der Heijden et al., 2015). Yet, to properly validate such a dramatic climate change-carbon feedback loop and to unravel the role lianas play therein, one needs to consider the interplay between the energy, the water, and the carbon cycles. Most studies that investigated the role of lianas have neglected those interactions, primarily focusing on a single biogeochemical cycle. As illustrated here, calibrated vegetation models are key to reveal the relative magnitude of 
all the interacting and contradictory impacts lianas have on forests, as well as the feedbacks they create.

While lianas remain largely ignored by vegetation models, we demonstrate here that they alter the energy balance and the carbon cycle of tropical forests, which is per se a strong argument to take them into account when predicting the future land carbon sink.

\section{ACKNOWLEDGEMENTS}

This research was funded by the European Research Council Starting Grant 637643 (TREECLIMBERS) and the Research Foundation Flanders (FWO), senior research project G002321N. The computational resources and services used in this work were provided by the VSC (Flemish Supercomputer Center), funded by the Research Foundation - Flanders (FWO) and the Flemish Government - department EWI. During the preparation of this manuscript, FM was first funded by the BAEF and the $\mathrm{WBI}$ as a research fellow and then by the FWO as a junior postdoc (fellowship $1214720 \mathrm{~N}$ ) and is thankful to these organizations for their financial support. HPTDD was also a BAEF research fellow during the preparation of this manuscript and is as grateful to this organization for its support. MCD was supported by NSF ABI grant 1458021 . We are grateful to the whole PEcAn group and the ED2 team for helpful discussions and support related to the functioning of BETY, PEcAn, and ED-RTM. The research carried out at the Jet Propulsion Laboratory, California Institute of Technology, was under a contract with the National Aeronautics and Space Administration. ML was supported by the NASA Postdoctoral Program, administered by Universities Space Research Association under contract with NASA. GatorEye data collection and processing by AMAZ and ENB was supported by the McIntire-Stennis program of the USDA and the University of Florida.

\section{CONFLICT OF INTEREST}

None declared.

\section{AUTHORS' CONTRIBUTIONS}

FM, MV, MD, and HV designed the study. FM implemented the workflow, ran the simulations, and processed the results with inputs and support from MD and AS for PEcAn and ED-RTM technical aspects. Some of the co-authors contributed critical data to calibrate or validate the model outputs, including MV and HML (WorldView-3), JAG and ASA (raw spectral data), and ENB and AMAZ (GatorEye LiDAR). All authors contributed to the manuscript and critically revised it.

\section{DATA AVAILABILITY STATEMENT}

The data that support the findings of this study are openly available in Zenodo at https://doi.org/10.5281/zenodo.5560918, reference number 5560918.

\section{ORCID}

Félicien Meunier (D) https://orcid.org/0000-0003-2486-309X Marco D. Visser (D) https://orcid.org/0000-0003-1200-0852 Alexey Shiklomanov (D) https://orcid.org/0000-0003-4022-5979 Michael C. Dietze (D) https://orcid.org/0000-0002-2324-2518
J. Antonio Guzmán Q. (D) https://orcid.org/0000-0002-0721-148X G. Arturo Sanchez-Azofeifa (D) https://orcid.org/0000-0001-7768-6600 Hannes P. T. De Deurwaerder (D) https://orcid. org/0000-0002-9287-2062

Sruthi M. Krishna Moorthy (D) https://orcid.org/0000-0002-6838-2880 Stefan A. Schnitzer (D) https://orcid.org/0000-0002-2715-9455

David C. Marvin (D) https://orcid.org/0000-0002-2938-9027

Marcos Longo (D) https://orcid.org/0000-0001-5062-6245

Chang Liu (D) https://orcid.org/0000-0002-2919-9717

Eben N. Broadbent (D) https://orcid.org/0000-0002-4488-4237

Angelica M. Almeyda Zambrano (D) https://orcid.

org/0000-0001-5081-9936

Helene C. Muller-Landau (D) https://orcid.org/0000-0002-3526-9021

Matteo Detto (D) https://orcid.org/0000-0003-0494-188X

Hans Verbeeck (D) https://orcid.org/0000-0003-1490-0168

\section{REFERENCES}

Ahlström, A., Canadell, J. G., Schurgers, G., Wu, M., Berry, J. A., Guan, K., \& Jackson, R. B. (2017). Hydrologic resilience and Amazon productivity. Nature Communications, 8, 387. https://doi.org/10.1038/ s41467-017-00306-z

Arias, P. A., Rong, F. U., Hoyos, C. D., Li, W., \& Zhou, L. (2011). Changes in cloudiness over the Amazon rainforests during the last two decades: Diagnostic and potential causes. Climate Dynamics, 37(5), 1151-1164. https://doi.org/10.1007/s00382-010-0903-2

Asner, G. P. (2008). Hyperspectral remote sensing of canopy chemistry, physiology, and biodiversity in tropical rainforests. In M. Kalacska \& G. A. Sanchez-Azofeifa (Eds.), Hyperspectral remote sensing of tropical and sub-tropical forests (pp. 261-296). CRC Press.

Asner, G. P., \& Alencar, A. (2010). Drought impacts on the Amazon forest: The remote sensing perspective. New Phytologist, 187, 569-578. https://doi.org/10.1111/j.1469-8137.2010.03310.x

Asner, G.P., \& Martin, R.E.(2012). Contrastingleafchemical traits in tropical lianas and trees: Implications for future forest composition. Ecology Letters, 15(9), 1001-1007. https://doi.org/10.1111/j.1461-0248.2012.01821.x

Avalos, G., \& Mulkey, S. S. (1999). Seasonal changes in liana cover in the upper canopy of a neotropical dry forest. Biotropica, 31(1), 186192. https://doi.org/10.2307/2663973

Avitabile, V., Herold, M., Heuvelink, G. B. M., Lewis, S. L., Phillips, O. L., Asner, G. P., Armston, J., Ashton, P. S., Banin, L., Bayol, N., Berry, N. J., Boeckx, P., Jong, B. H. J., DeVries, B., Girardin, C. A. J., Kearsley, E., Lindsell, J. A., Lopez-Gonzalez, G., Lucas, R., ... Willcock, S. (2016). An integrated pan-tropical biomass map using multiple reference datasets. Global Change Biology, 22(4), 1406-1420. https://doi.org/10.1111/gcb.13139

Beer, C., Reichstein, M., Tomelleri, E., Ciais, P., Jung, M., Carvalhais, N., Rödenbeck, C., Arain, M. A., Baldocchi, D., Bonan, G. B., Bondeau, A., Cescatti, A., Lasslop, G., Lindroth, A., Lomas, M., Luyssaert, S., Margolis, H., Oleson, K. W., Roupsard, O., ... Papale, D. (2010). Terrestrial gross carbon dioxide uptake: Global distribution and covariation with climate. Science, 329(5993), 834-838. https://doi. org/10.1126/science.1184984

Best, M. J., Pryor, M., Clark, D. B., Rooney, G. G., Essery, R. L. H., Ménard, C. B., Edwards, J. M., Hendry, M. A., Porson, A., Gedney, N., Mercado, L. M., Sitch, S., Blyth, E., Boucher, O., Cox, P. M., Grimmond, C. S. B., \& Harding, R. J. (2011). The Joint UK Land Environment Simulator (JULES), model description-Part 1: Energy and water fluxes. Geoscientific Model Development, 4(3), 677-699. https://doi.org/10.5194/gmd-4-677-2011

Bonan, G. B. (2008). Forests and climate change: Forcings, feedbacks, and the climate benefits of forests. Science, 320(5882), 1444-1449. https://doi.org/10.1126/science.1155121 
Bonan, G. (2019). Climate change and terrestrial ecosystem modeling (1st ed.). Cambridge University Press. https://doi.org/10.1017/97811 07339217

Bongers, F., Ewango, C. E. N., van der Sande, M. T., \& Poorter, L. (2020). Liana species decline in congo basin contrasts with global patterns. Ecology, 101(5), e03004. https://doi.org/10.1002/ecy.3004

Bongers, F., \& Sterck, F. J. (Department of Forestry Sterck). (1998). Architecture and development of rainforest trees: Responses to light variation. http://agris.fao.org/agris-search/search.do?recor dID $=$ GB1997050682

Brienen, R. J. W., Phillips, O. L., Feldpausch, T. R., Gloor, E., Baker, T. R., Lloyd, J., Lopez-Gonzalez, G., Monteagudo-Mendoza, A., Malhi, Y., Lewis, S. L., Vásquez Martinez, R., Alexiades, M., Álvarez Dávila, E., Alvarez-Loayza, P., Andrade, A., Aragão, L. E. O. C., AraujoMurakami, A., Arets, E. J. M. M., Arroyo, L., ... Zagt, R. J. (2015). Long-term decline of the Amazon carbon sink. Nature, 519, 344348. https://doi.org/10.1038/nature14283

Brinck, K., Fischer, R., Groeneveld, J., Lehmann, S., Paula, M. D. D., Pütz, S., Sexton, J. O., Song, D., \& Huth, A. (2017). High resolution analysis of tropical forest fragmentation and its impact on the global carbon cycle. Nature Communications, 8(1), 1-6. https://doi.org/10.1038/ ncomms14855

Castro-Esau, K., Sanchez-Azofeifa, G. A., \& Caelli, T. (2004). Discrimination of lianas and trees with leaf-level hyperspectral data. Remote Sensing of Environment, 90(3), 353-372. https://doi. org/10.1016/j.rse.2004.01.013

Chen, Y.-J., Cao, K.-F., Schnitzer, S. A., Fan, Z.-X., Zhang, J.-L., \& Bongers, F. (2015). Water-use advantage for lianas over trees in tropical seasonal forests. New Phytologist, 205(1), 128-136. https://doi. org/10.1111/nph.13036

Chen, Y. J., Schnitzer, S. A., Zhang, Y. J., Fan, Z. X., Goldstein, G., Tomlinson, K. W., Lin, H., Zhang, J. L., \& Cao, K. F. (2017). Physiological regulation and efficient xylem water transport regulate diurnal water and carbon balances of tropical lianas. Functional Ecology, 31(2), 306-317. https://doi. org/10.1111/1365-2435.12724

Condit, R., Pérez, R., Aguilar, S., Lao, S., Foster, R., \& Hubbell, S. (2019). Complete data from the Barro Colorado 50-Ha plot: 423617 trees, 35 years. Smithsonian Center for Tropical Forest Science. https:// doi.org/10.15146/5xcp-0d46

Cooley, T., Anderson, G. P., Felde, G. W., Hoke, M. L., Ratkowski, A. J., Chetwynd, J. H., Gardner, J. A.,Adler-Golden, S. M., Matthew, M. W., Berk, A., Bernstein, L. S., Acharya, P. K., Miller, D., \& Lewis, P. (2002). FLAASH, a MODTRAN4-based atmospheric correction algorithm, its application and validation. In IEEE international geoscience and remote sensing symposium (Vol. 3, pp. 1414-1418). IEEE. https://doi.org/10.1109/IGARSS.2002.1026134

Detto, M., Joseph Wright, S., Calderón, O., \& Muller-Landau, H. C. (2018). Resource acquisition and reproductive strategies of tropical forest in response to the EI Niño-southern oscillation. Nature Communications, 9(1), 1-8. https://doi.org/10.1038/s41467-018-03306-9

Dewalt, S. J., Schnitzer, S. A., Alves, L. F., Bongers, F., Burnham, R. J., Cai, Z., Carson, W. P., Chave, J., Chuyong, G. B., Costa, F. R. C., Ewango, C. E. N., Gallagher, R. V., Gerwing, J. J., Amezcua, E. G., Hart, T., Ibarra-Manríquez, G., Ickes, K., Kenfack, D., Letcher, S. G., ... van Melis, J. (2014). Biogeographical patterns of liana abundance and diversity. Ecology of Lianas, 131-146. https://doi.org/10.1002/97811 18392409.ch11

Dietze, M. C., Serbin, S. P., Davidson, C., Desai, A. R., Feng, X., Kelly, R., Kooper, R., LeBauer, D., Mantooth, J., McHenry, K., \& Wang, D. (2014). A quantitative assessment of a terrestrial biosphere model's data needs across north American biomes. Journal of Geophysical Research: Biogeosciences, 119(3), 286-300. https://doi. org/10.1002/2013JG002392

Dietze, M. C., Wolosin, M. S., \& Clark, J. S. (2008). Capturing diversity and interspecific variability in allometries: A hierarchical approach.
Forest Ecology and Management, 256(11), 1939-1948. https://doi. org/10.1016/j.foreco.2008.07.034

di Porcia e Brugnera, M., Meunier, F., Longo, M., Krishna Moorthy, S. M. De Deurwaerder, H., Schnitzer, S. A., Bonal, D., Faybishenko, B., \& Verbeeck, H. (2019). Modeling the impact of liana infestation on the demography and carbon cycle of tropical forests. Global Change Biology, 25(11), 3767-3780. https://doi.org/10.1111/gcb.14769

Doughty, C. E., Santos-Andrade, P. E., Shenkin, A., Goldsmith, G. R., Bentley, L. P., Blonder, B., Díaz, S., Salinas, N., Enquist, B. J., Martin R. E., Asner, G. P., \& Malhi, Y. (2018). Tropical forest leaves may darken in response to climate change. Nature Ecology \& Evolution, 2(12), 1918-1924. https://doi.org/10.1038/s41559-018-0716-y

Elzhov, T. V., Mullen, K. M., Spiess, A.-N., \& Bolker, B.. (2016). Minpack. $L m: R$ interface to the Levenberg-Marquardt nonlinear least-squares algorithm found in MINPACK, plus support for bounds (version 1.2-1). https://CRAN.R-project.org/package=minpack.Im

Estrada-Villegas, S., \& Schnitzer, S. A. (2018). A comprehensive synthesis of liana removal experiments in tropical forests. Biotropica, 50(5), 729-739. https://doi.org/10.1111/btp.12571

Falster, D. S., Duursma, R. A., Ishihara, M. I., Barneche, D. R., FitzJohn, R. G., Vårhammar, A., Aiba, M., Ando, M., Anten, N., Aspinwall, M. J., Baltzer, J. L., Baraloto, C., Battaglia, M., Battles, J. J., BondLamberty, B., van Breugel, M., Camac, J., Claveau, Y., Coll, L., ... York, R. A. (2015). BAAD: A biomass and allometry database for woody plants. Ecology, 96(5), 1445. https://doi.org/10.1890/14-1889.1

Feret, J.-B., François, C., Asner, G. P., Gitelson, A. A., Martin, R. E., Bidel, L. P. R., Ustin, S. L., le Maire, G., \& Jacquemoud, S. (2008). PROSPECT-4 and 5: Advances in the leaf optical properties model separating photosynthetic pigments. Remote Sensing of Environment, 112, 3030-3043. https://doi.org/10.1016/j.rse.2008.02.012

Fischlin, A., Midgley, G. F., Price, J., Leemans, R., Gopal, B., Turley, C., Rounsevell, M., Dube, P., Tarazona, J., \& Velichko, A.. (2007). Ecosystems, their properties, goods, and services. In M. L. Parry, O. F. Canziani, J. P. Palutikof, P. J. van Der Linden, \& C. E. Hanson (Eds.), Climate change 2007: Impacts, adaptation and vulnerability. Contribution of working group II to the fourth assessment report of the Intergovernmental Panel on Climate Change (pp. 211-272). Cambridge University Press.

Fisher, J. B., Huntzinger, D. N., Schwalm, C. R., \& Sitch, S. (2014). Modeling the terrestrial biosphere. Annual Review of Environment and Resources, 39(1), 91-123. https://doi.org/10.1146/annurevenviron-012913-093456

Fisher, R. A., Koven, C. D., Anderegg, W. R. L., Christoffersen, B. O., Dietze, M. C., Farrior, C. E., Holm, J. A., Hurtt, G. C., Knox, R. G. Lawrence, P. J., Lichstein, J. W., Longo, M., Matheny, A. M., Medvigy, D., Muller-Landau, H. C., Powell, T. L., Serbin, S. P., Sato, H., Shuman, J. K., ... Moorcroft, P. R. (2018). Vegetation demographics in earth system models: A review of progress and priorities. Global Change Biology, 24(1), 35-54. https://doi.org/10.1111/gcb.13910

Fisher, R., McDowell, N., Purves, D., Moorcroft, P., Sitch, S., Cox, P., Huntingford, C., Meir, P., \& Ian Woodward, F. (2010). Assessing uncertainties in a second-generation dynamic vegetation model caused by ecological scale limitations. New Phytologist, 187(3), 666681. https://doi.org/10.1111/j.1469-8137.2010.03340.x

Foster, J. R., Townsend, P. A., \& Zganjar, C. E. (2008). Spatial and temporal patterns of gap dominance by low-canopy lianas detected using EO-1 Hyperion and Landsat Thematic Mapper. Remote Sensing of Environment, 112, 2104-2117. https://doi.org/10.1016/j.rse.2007.07.027

Fu, R., Yin, L., Li, W., Arias, P. A., Dickinson, R. E., Huang, L., Chakraborty, S., Fernandes, K., Liebmann, B., Fisher, R., \& Myneni, R. B. (2013). Increased dry-season length over southern Amazonia in recent decades and its implication for future climate projection. Proceedings of the National Academy of Sciences of the United States of America, 110(45), 18110-18115. https://doi.org/10.1073/pnas.1302584110

Gehring, C., Park, S., \& Denich, M. (2004). Liana allometric biomass equations for amazonian primary and secondary forest. Forest Ecology 
and Management, 195(1-2), 69-83. https://doi.org/10.1016/j. foreco.2004.02.054

Gerwing, J. J., \& Farias, D. L. (2000). Integrating liana abundance and forest stature into an estimate of total aboveground biomass for an eastern amazonian forest. Journal of Tropical Ecology, 16(3), 327335. https://doi.org/10.1017/S0266467400001437

Gong, P., Ruiliang, P. U., Biging, G. S., \& Larrieu, M. R. (2003). Estimation of forest leaf area index using vegetation indices derived from hyperion hyperspectral data. IEEE Transactions on Geoscience and Remote Sensing, 41(6), 1355-1362. https://doi.org/10.1109/ TGRS.2003.812910

Goudriaan, 1977Goudriaan, J. (1977). Crop micrometeorology: A simulation study. Pudoc. https://library.wur.nl/WebQuery/wurpubs/70980

Guzmán, Q., Antonio, J., Rivard, B., \& Arturo Sánchez-Azofeifa, G. (2018). Discrimination of liana and tree leaves from a neotropical dry forest using visible-near infrared and longwave infrared reflectance spectra. Remote Sensing of Environment, 219(December), 135-144. https://doi.org/10.1016/j.rse.2018.10.014

Hartig, F., Minunno, F., Paul, S., Cameron, D., Ott, T., \& Pichler, M. (2019). BayesianTools: General-purpose MCMC and SMC samplers and tools for Bayesian statistics (version 0.1.7). https://CRAN.R-project.org/ package $=$ BayesianTools

Jacquemoud, S., Bacour, C., Poilvé, H., \& Frangi, J.-P. (2000). Comparison of four radiative transfer models to simulate plant canopies reflectance: Direct and inverse mode. Remote Sensing of Environment, 74(3), 471-481. https://doi.org/10.1016/S0034-4257(00)00139-5

Kalacska, M., Bohlman, S., Sanchez-Azofeifa, G. A., Castro-Esau, K., \& Caelli, T. (2007). Hyperspectral discrimination of tropical dry forest lianas and trees: Comparative data reduction approaches at the leaf and canopy levels. Remote Sensing of Environment, 109(4), 406-415. https://doi.org/10.1016/j.rse.2007.01.012

Kazda, M., \& Salzer, J. (2000). Leaves of lianas and self-supporting plants differ in mass per unit area and in nitrogen content. Plant Biology, 2 268-271. https://doi.org/10.1055/s-2000-3701

Konapala, G., Mishra, A. K., Wada, Y., \& Mann, M. E. (2020). Climate change will affect global water availability through compounding changes in seasonal precipitation and evaporation. Nature Communications, 11(1), 3044. https://doi.org/10.1038/s41467020-16757-w

Koricheva, J., Gurevitch, J., \& Mengersen, K. (Eds.). (2013). Handbook of meta-analysis in ecology and evolution (2013th ed.). Princeton University Press.

Kurzel, B. P., Schnitzer, S. A., \& Carson, W. P. (2006). Predicting liana crown location from stem diameter in three Panamanian lowland forests. Biotropica, 38(2), 262-266. https://doi. org/10.1111/j.1744-7429.2006.00135.x

Lawrence, D. M., Fisher, R. A., Koven, C. D., Oleson, K. W., Swenson, S. C., Bonan, G., Collier, N., Ghimire, B., Kampenhout, L., Kennedy, D., Kluzek, E., Lawrence, P. J., Li, F., Li, H., Lombardozzi, D., Riley, W. J., Sacks, W. J., Shi, M., Vertenstein, M., ... Zeng, X. (2019). The community land model version 5: Description of new features, benchmarking, and impact of forcing uncertainty. Journal of Advances in Modeling Earth Systems, 11(12), 4245-4287. https://doi. org/10.1029/2018MS001583

LeBauer, D. S., Wang, D., Richter, K. T., Davidson, C. C., \& Dietze, M. C. (2013). Facilitating feedbacks between field measurements and ecosystem models. Ecological Monographs, 83(2), 133-154. https:// doi.org/10.1890/12-0137.1

Ledo, A., \& Schnitzer, S. A. (2014). Disturbance and clonal reproduction determine liana distribution and maintain liana diversity in a tropical forest. Ecology, 95, 2169-2178. https://doi.org/10.1890/13-1775.1

Liou, K. N. (2002). An introduction to atmospheric radiation (Vol. 84). International Geophysics Series. https://books.google.com/ books/about/An_Introduction_to_Atmospheric_Radiation.html?id=mQ1DiDpX34UC
Longo, M., Knox, R. G., Medvigy, D. M., Levine, N. M., Dietze, M. C., Kim, Y., Swann, A. L. S., Zhang, K., Rollinson, C. R., Bras, R. L., Wofsy, S. C., \& Moorcroft, P. R. (2019a). The biophysics, ecology, and biogeochemistry of functionally diverse, vertically and horizontally heterogeneous ecosystems: The Ecosystem Demography model, version 2.2-Part 1: Model description. Geoscientific Model Development, 12, 4309-4346. https://doi.org/10.5194/gmd-12-4309-2019

Longo, M., Knox, R. G., Levine, N. M., Swann, A. L. S., Medvigy, D. M., Dietze, M. C., Kim, Y., Zhang, K., Bonal, D., Burban, B., Camargo, P. B., Hayek, M. N., Saleska, S. R., da Silva, R., Bras, R. L., Wofsy, S. C., \& Moorcroft, P. R. (2019b). The biophysics, ecology, and biogeochemistry of functionally diverse, vertically and horizontally heterogeneous ecosystems: the Ecosystem Demography model, version 2.2-Part 2: Model evaluation for tropical South America. Geoscientific Model Development, 12, 4347-4374. https://doi. org/10.5194/gmd-12-4347-2019

Longo, M., Saatchi, S., Keller, M., Bowman, K., Ferraz, A., Moorcroft, P. R., Morton, D. C., Bonal, D., Brando, P., Burban, B., Derroire, G., dos-Santos, M. N., Meyer, V., Saleska, S., Trumbore, S., \& Vincent, G. (2020). Impacts of degradation on water, energy, and carbon cycling of the amazon tropical forests. Journal of Geophysical Research: Biogeosciences, 125(8), e2020JG005677. https://doi. org/10.1029/2020JG005677

Marvin, D. C., Asner, G. P., \& Schnitzer, S. A. (2016). Liana canopy cover mapped throughout a tropical forest with high-fidelity imaging spectroscopy. Remote Sensing of Environment, 176, 98-106. https:// doi.org/10.1016/j.rse.2015.12.028

Medvigy, D., Wofsy, S. C., Munger, J. W., Hollinger, D. Y., \& Moorcroft, P. R. (2009). Mechanistic scaling of ecosystem function and dynamics in space and time: Ecosystem demography model version 2. Journal of Geophysical Research, 114(G1), https://doi.org/10.1029/2008J G000812

Meroni, M., Colombo, R., \& Panigada, C. (2004). Inversion of a radiative transfer model with hyperspectral observations for LAI mapping in poplar plantations. Remote Sensing of Environment, 92(2), 195-206. https://doi.org/10.1016/j.rse.2004.06.005

Meunier, F., Verbeeck, H., Cowdery, B., Schnitzer, S. A., Chris, M., SmithMartin, J. P., Xiangtao, X. U., Slot, M., Deurwaerder, H. P. T., Detto, M., Bonal, D., Longo, M., Santiago, L. S., \& Dietze, M. (2020). Unraveling the relative role of light and water competition between lianas and trees in tropical forests. Journal of Ecology, 109, 519-540. https://doi.org/10.1111/1365-2745.13540

Mitchard, E. T. A. (2018). The tropical forest carbon cycle and climate change. Nature, 559(7715), 527-534. https://doi.org/10.1038/ s41586-018-0300-2

Moorthy, K., \& Sruthi, M. (2019). Assessing the role of lianas in tropical forest structure with terrestrial LiDAR. Dissertation, Ghent University. http://hdl.handle.net/1854/LU-8636809

Oleson, K., Lawrence, M., Bonan, B., Drewniak, B., Huang, M., Koven, D., Levis, S., Li, F., Riley, J., Subin, M., Swenson, S., Thornton, E., Bozbiyik, A., Fisher, R., Heald, L., Kluzek, E., Lamarque, J.-F., Lawrence, J., Leung, R., ... Yang, Z.-L. (2013). Technical description of version 4.5 of the Community Land Model (CLM). https://doi. org/10.5065/D6RR1W7M

Olivas, P. C., Oberbauer, S. F., Clark, D. B., Clark, D. A., Ryan, M. G., O'Brien, J. J., \& Ordoñez, H. (2013). Comparison of direct and indirect methods for assessing leaf area index across a tropical rain forest landscape. Agricultural \& Forest Meteorology, 177, 110-116. https://doi.org/10.1016/j.agrformet.2013.04.010

Pan, Y., Birdsey, R. A., Fang, J., Houghton, R., Kauppi, P. E., Kurz, W. A., Phillips, O. L., Shvidenko, A., Lewis, S. L., Canadell, J. G., Ciais, P., Jackson, R. B., Pacala, S. W., McGuire, A. D., Piao, S., Rautiainen, A., Sitch, S., \& Hayes, D. (2011). A large and persistent carbon sink in the world's forests. Science, 333(6045), 988-993. https://doi. org/10.1126/science.1201609 
Park, J. Y., Muller-Landau, H. C., Lichstein, J. W., Rifai, S. W., Dandois, J. P., \& Bohlman, S. A. (2019). Quantifying leaf phenology of individual trees and species in a tropical forest using unmanned aerial vehicle (UAV) images. Remote Sensing, 11(13), 1534. https://doi. org/10.3390/rs11131534

Pau, S., Detto, M., Kim, Y., \& Still, C. J. (2018). Tropical forest temperature thresholds for gross primary productivity. Ecosphere, 9(7), e02311. https://doi.org/10.1002/ecs2.2311

Phillips, O. L., Vásquez Martínez, R., Arroyo, L., Baker, T. R., Killeen, T., Lewis, S. L., Malhi, Y., Monteagudo Mendoza, A., Neill, D., Núñez Vargas, P., Alexiades, M., Cerón, C., Di Fiore, A., Erwin, T., Jardim, A., Palacios, W., Saldias, M., \& Vinceti, B. (2002). Increasing dominance of large lianas in Amazonian forests. Nature, 418(6899), 770774. https://doi.org/10.1038/nature00926

Piao, S., Wang, X., Park, T., Chen, C., Lian, X. U., He, Y., Bjerke, J. W., Chen, A., Ciais, P., Tømmervik, H., Nemani, R. R., \& Myneni, R. B. (2020). Characteristics, drivers and feedbacks of global greening. Nature Reviews Earth \& Environment, 1(1), 14-27. https://doi.org/10.1038/ s43017-019-0001-x

Poorter, L., Bongers, F., Sterck, F. J., \& Wöll, H. (2003). Architecture of 53 rain forest tree species differing in adult stature and shade tolerance. Ecology, 84(3), 602-608.

Powell, T. L., Galbraith, D. R., Christoffersen, B. O., Harper, A., Imbuzeiro, H. M. A., Rowland, L., Almeida, S., Brando, P. M., Costa, A. C. L., Costa, M. H., Levine, N. M., Malhi, Y., Saleska, S. R., Sotta, E., Williams, M., Meir, P., \& Moorcroft, P. R. (2013). Confronting model predictions of carbon fluxes with measurements of Amazon forests subjected to experimental drought. The New Phytologist, 200(2), 350-365. https://doi.org/10.1111/nph.12390

Powell, T. L., Koven, C. D., Johnson, D. J., Faybishenko, B., Fisher, R. A., Knox, R. G., McDowell, N. G., Condit, R., Hubbell, S. P., Wright, S. J., Chambers, J. Q., \& Kueppers, L. M. (2018). Variation in hydroclimate sustains tropical forest biomass and promotes functional diversity. New Phytologist, 219(3), 932-946. https://doi.org/10.1111/nph.15271

Powell, T., Kueppers, L., \& Paton, S.. (2017). Seven years (2008-2014) of meteorological observations plus a synthetic El Nino drought for $\mathrm{BCl}$ Panama. Next-Generation Ecosystem Experiments Tropics; Lawrence Berkeley National Laboratory (see acknowledgements below for the source of the original raw data). https://doi. org/10.15486/ngt/1414275

Purves, D., \& Pacala, S. (2008). Predictive models of forest dynamics. Science, 320(5882), 1452-1453. https://doi.org/10.1126/scien ce.1155359

Putz, F. E. (1983). Liana biomass and leaf area of a "tierra firme" forest in the Rio Negro Basin, Venezuela. Biotropica, 15(3), 185-189. https:// doi.org/10.2307/2387827

Reis, S. M., Marimon, B. S., Morandi, P. S., Elias, F., Esquivel-Muelbert, A., Marimon Junior, B. H., Fauset, S., Oliveira, E. A., Heijden, G. M. F., Galbraith, D., Feldpausch, T. R., \& Phillips, O. L. (2020). Causes and consequences of liana infestation in Southern Amazonia. Journal of Ecology, 108(6), 2184-2197. https://doi. org/10.1111/1365-2745.13470

Sánchez-Azofeifa, G. A., \& Castro-Esau, K. (2006). Canopy observations on the hyperspectral properties of a community of tropical dry forest lianas and their host trees. International Journal of Remote Sensing, 27(10), 2101-2109. https://doi.org/10.1080/0143116050 0444749

Sánchez-Azofeifa, G. A., Karen Castro, S., Wright, J., Gamon, J., Kalacska, M., Rivard, B., Schnitzer, S. A., \& Feng, J. L. (2009). Differences in leaf traits, leaf internal structure, and spectral reflectance between two communities of lianas and trees: Implications for remote sensing in tropical environments. Remote Sensing of Environment, 113(10), 2076-2088. https://doi.org/10.1016/j.rse.2009.05.013

Schnitzer, S. A. (2005). A mechanistic explanation for global patterns of liana abundance and distribution. The American Naturalist, 166(2), 262-276. https://doi.org/10.1086/431250
Schnitzer, S. A., \& Bongers, F. (2002). The ecology of lianas and their role in forests. Trends in Ecology \& Evolution, 17(5), 223-230. https://doi. org/10.1016/S0169-5347(02)02491-6

Schnitzer, S. A., \& Bongers, F. (2011). Increasing liana abundance and biomass in tropical forests: Emerging patterns and putative mechanisms. Ecology Letters, 14(4), 397-406. https://doi. org/10.1111/j.1461-0248.2011.01590.x

Schnitzer, S. A., DeWalt, S. J., \& Chave, J. (2006). Censusing and measuring lianas: A quantitative comparison of the common methods. Biotropica, 38(5), 581-591. https://doi. org/10.1111/j.1744-7429.2006.00187.x

Schnitzer, S. A., Kuzee, M. E., \& Bongers, F. (2005). Disentangling aboveand below-ground competition between lianas and trees in a tropical forest. Journal of Ecology, 93(6), 1115-1125. https://doi. org/10.1111/j.1365-2745.2005.01056.x

Schnitzer, S. A., Mangan, S. A., Dalling, J. W., Baldeck, C. A., Hubbell, S. P., Ledo, A., Muller-Landau, H., Tobin, M. F., Aguilar, S., Brassfield, D. Hernandez, A., Lao, S., Perez, R., Valdes, O., \& Yorke, S. R. (2012). Liana abundance, diversity, and distribution on Barro Colorado Island, Panama. PLoS ONE, 7(12), e52114. https://doi.org/10.1371/ journal.pone.0052114

Schnitzer, S. A., \& van der Heijden, G. M. F. (2019). Lianas have a seasonal growth advantage over co-occurring trees. Ecology, 100(5), e02655. https://doi.org/10.1002/ecy.2655

Selaya, N. G., \& Anten, N. P. R. (2008). Differences in biomass allocation, light interception and mechanical stability between lianas and trees in early secondary tropical forest. Functional Ecology, 22, 30-39. https://doi.org/10.1111/j.1365-2435.2007.01350.x

Sellers, P. J. (1985). Canopy reflectance, photosynthesis and transpiration. International Journal of Remote Sensing, 6(8), 1335-1372. https://doi.org/10.1080/01431168508948283

Serbin, S. P., Singh, A., Desai, A. R., Dubois, S. G., Jablonski, A. D., Kingdon, C. C., Kruger, E. L., \& Townsend, P. A. (2015). Remotely estimating photosynthetic capacity, and its response to temperature, in vegetation canopies using imaging spectroscopy. Remote Sensing of Environment, 167(September), 78-87. https://doi.org/10.1016/j. rse.2015.05.024

Shiklomanov, A. N., Bond-Lamberty, B., Atkins, J. W., \& Gough, C. M. (2020). Structure and parameter uncertainty in centennial projections of forest community structure and carbon cycling. Global Change Biology, 26(11), 6080-6096. https://doi.org/10.1111/gcb.15164

Shiklomanov, A. N., Dietze, M. C., Fer, I., Viskari, T., \& Serbin, S. P. (2020). Cutting out the middleman: Calibrating and validating a dynamic vegetation model (ED2-PROSPECT5) using remotely sensed surface reflectance. Geoscientific Model Development Discussions, October, 1-35. https://doi.org/10.5194/gmd-2020-324

Shiklomanov, A. N., Dietze, M. C., Viskari, T., Townsend, P. A., \& Serbin, S. P. (2016). Quantifying the influences of spectral resolution on uncertainty in leaf trait estimates through a Bayesian approach to RTM inversion. Remote Sensing of Environment, 183(September), 226-238. https://doi.org/10.1016/j.rse.2016.05.023

Smith-Martin, C. M., Xiangtao, X. U., Medvigy, D., Schnitzer, S. A., \& Powers, J. S. (2020). Allometric scaling laws linking biomass and rooting depth vary across ontogeny and functional groups in tropical dry forest lianas and trees. New Phytologist, 226(3), 714-726. https://doi.org/10.1111/nph.16275

Spracklen, D. V., Baker, J. C. A., Garcia-Carreras, L., \& Marsham, J. H. (2018). The effects of tropical vegetation on rainfall. Annual Review of Environment and Resources, 43(1), 193-218. https://doi. org/10.1146/annurev-environ-102017-030136

Stevens, G. C. (1987). Lianas as structural parasites: The bursera simaruba example published by: Ecological Society of America linked references are available on JSTOR for this article. Ecology, 68(1), 77-81.

ter Braak, C. J. F., \& Vrugt, J. A. (2008). Differential evolution markov chain with snooker updater and fewer chains. Statistics and Computing, 18(4), 435-446. https://doi.org/10.1007/s11222-008-9104-9 
van der Heijden, G., Powers, J. S., \& Schnitzer, S. A. (2015). Lianas reduce forest-level carbon accumulation and storage. Proceedings of the National Academy of Sciences of the United States of America, 112(43), 13267-13271. https://doi.org/10.1073/pnas.1504869112

van der Heijden, G. M., Schnitzer, S. A., Powers, J. S., \& Phillips, O. L. (2013). Liana impacts on carbon cycling, storage and sequestration in tropical forests. Biotropica, 45(6), 682-692. https://doi. org/10.1111/btp.12060

van der Sande, M. T., Poorter, L., Schnitzer, S. A., \& Markesteijn, L. (2013). Are lianas more drought-tolerant than trees? A test for the role of hydraulic architecture and other stem and leaf traits. Oecologia, 172(4), 961-972. https://doi.org/10.1007/s00442-012-2563-x

Verbeeck, H., \& Kearsley, E. (2016). The importance of including lianas in global vegetation models. Proceedings of the National Academy of Sciences of the United States of America, 113(1), E4. https://doi. org/10.1073/pnas.1521343113

Viskari, T., Shiklomanov, A., Dietze, M. C., \& Serbin, S. P. (2019). The influence of canopy radiation parameter uncertainty on model projections of terrestrial carbon and energy cycling. PLoS ONE, 14(7), e0216512. https://doi.org/10.1371/journal.pone.0216512

Visser, M. D., Detto, M., Meunier, F., Wu, J., Foster, J., Marvin, D. C., Bongalov, B., Nunes, M. H., Coomes, D., Verbeeck, H., Antonio Guzmán Q., J., Sanchez-Azofeifa, A., Chandler, C. J., van der Heijden, G. M. F., Boyd, D. S., Foody, G. M., Cutler, M. E. J., Broadbent, E. N., Serbin, S. S., ... Pacala, S. (2021). Why can we detect lianas from space? bioRxiv. https://doi.org/10.1101/2021.09.30.462145

Wyka, T. P., Oleksyn, J., Karolewski, P., \& Schnitzer, S. A. (2013). Phenotypic correlates of the lianescent growth form: A review. Annals of Botany, 112, 1667-1681. https://doi.org/10.1093/aob/mct236
Xu, X., Medvigy, D., Powers, J. S., Becknell, J. M., \& Guan, K. (2016). Diversity in plant hydraulic traits explains seasonal and inter-annual variations of vegetation dynamics in seasonally dry tropical forests. New Phytologist, 212(1), 80-95. https://doi.org/10.1111/nph.14009

Yuan, C.-M., Wu, T., Geng, Y.-F., Chai, Y., \& Hao, J.-B. (2016). Phenotypic plasticity of lianas in response to altered light environment. Ecological Research, 31(3), 375-384. https://doi.org/10.1007/s1128 4-016-1343-1

\section{SUPPORTING INFORMATION}

Additional supporting information may be found in the online version of the article at the publisher's website.

How to cite this article: Meunier, F., Visser, M. D., Shiklomanov, A., Dietze, M. C., Guzmán Q., J. A., SanchezAzofeifa, G. A., De Deurwaerder, H. P. T., Krishna Moorthy, S. M., Schnitzer, S. A., Marvin, D. C., Longo, M., Liu, C., Broadbent, E. N., Almeyda Zambrano, A. M., Muller-Landau, H. C., Detto, M., \& Verbeeck, H. (2021). Liana optical traits increase tropical forest albedo and reduce ecosystem productivity. Global Change Biology, 00, 1-18. https://doi. org/10.1111/gcb.15928 